\title{
Population pharmacokinetics and exposure-response modeling and simulation for evolocumab in healthy volunteers and patients with hypercholesterolemia
}

\author{
Mita Kuchimanchi ${ }^{1} \cdot$ Anita Grover $^{1} \cdot$ Maurice G. Emery $^{1} \cdot$ Ransi Somaratne $^{1} \cdot$ Scott M. Wasserman ${ }^{1}$. \\ John P. Gibbs ${ }^{1} \cdot$ Sameer Doshi ${ }^{1}$
}

Received: 20 October 2017 / Accepted: 24 April 2018/ Published online: 7 May 2018

(c) The Author(s) 2018

\begin{abstract}
Evolocumab, a novel human monoclonal antibody, inhibits proprotein convertase subtilisin/kexin type 9, a protein that targets low-density lipoprotein-cholesterol (LDL-C) receptors for the treatment of hyperlipidemia. The primary objective of this analysis was to characterize the population pharmacokinetics (popPK) and exposure-response relationship of evolocumab to assess if dose adjustment is needed across differing patient populations. Data were pooled for 5474 patients in 11 clinical studies who received evolocumab doses of 7-420 mg at various frequencies, either intravenously or subcutaneously. Evolocumab area under concentration-time curve from 8 to 12 weeks $\left(\mathrm{AUC}_{\mathrm{wk} 8-12}\right)$ was simulated for individuals using the popPK model and was used to predict the LDL-C response in relation to $\mathrm{AUC}_{\mathrm{wk} 8-12}$. Evolocumab was eliminated through nonspecific (linear) and target-mediated (nonlinear) clearance. PopPK parameters and associated variabilities of evolocumab were similar to those of other monoclonal antibodies. The exposure-response model predicted a maximal 66\% reduction in LDL-C from baseline to the mean of weeks 10 and 12 for doses of evolocumab $140 \mathrm{mg}$ subcutaneously every 2 weeks or $420 \mathrm{mg}$ subcutaneously once monthly. After inclusion of statistically significant covariates in an uncertainty-based simulation, LDL-C reduction from baseline at the mean of weeks 10 and 12 was predicted to be within $74 \%$ to $126 \%$ of the reference patient for all simulated patient groups. Evolocumab had nonlinear pharmacokinetics. The range of responses based on intrinsic and extrinsic factors was not predicted to be sufficiently different from the reference patient to warrant evolocumab dose adjustment.
\end{abstract}

Keywords Evolocumab - PCSK9 - Population pharmacokinetics - Exposure-response - Monoclonal antibody · Hypercholesterolemia

\section{Introduction}

Reduction of low-density lipoprotein-cholesterol (LDL-C) is a primary target for pharmacotherapy in patients with cardiovascular disease [1]. LDL receptor (LDLR) recycling plays a critical role in the maintenance of cellular and wholebody cholesterol balance by regulating plasma LDL-C levels [2]. Proprotein convertase subtilisin/kexin type 9 (PCSK9)

Mita Kuchimanchi and Anita Grover are co-lead authors; John P. Gibbs and Sameer Doshi provided oversight for the work.

Sameer Doshi

sdoshi@amgen.com

1 Amgen Inc., One Amgen Center Dr, Thousand Oaks, CA, USA binds to the LDLR and promotes degradation of the LDLR within hepatocytes, thereby decreasing the recycling of LDLR and increasing LDL-C concentrations [3, 4]. Several studies report that statins increase PCSK9 [5-7], which may attenuate the cholesterol-lowering effect of statins [8]. Therefore, use of a PCSK9-antagonizing therapy is a particularly effective strategy in combination with a statin to lower LDL-C and improve dyslipidemia.

Evolocumab is a fully human monoclonal immunoglobulin G2 antibody that binds to human PCSK9 with high specificity and prevents the interaction of PCSK9 with LDLR. Inhibition of PCSK9 by evolocumab leads to increased LDLR expression and decreased circulating concentrations of LDL-C [9]. In phase 1, 2, and 3 clinical studies, evolocumab was administered subcutaneously (SC) at doses ranging from 7 to $420 \mathrm{mg}$, either alone or in 
combination with statins. At doses of at least $140 \mathrm{mg}$, there is effective PCSK9 inhibition, which translates into a reduction of LDL-C by $54-80 \%$ [10].

Following single-dose administration of evolocumab over a wide dose range (7-420 $\mathrm{mg}$ ) by intravenous (IV) or $\mathrm{SC}$ routes in healthy subjects, evolocumab exhibited nonlinear pharmacokinetics (PK) that could be described by parallel linear and nonlinear clearance [11, 12]. After multiple doses of $140 \mathrm{mg} \mathrm{SC}$ or higher, the nonlinear target-mediated elimination pathway was nearly saturated, and the linear elimination pathway was dominant [11]. In addition, there was no evidence of time-dependent PK after repeated dosing with the evolocumab regimens that were examined [13]. Randomized controlled studies have shown the efficacy and safety of evolocumab in a variety of patient populations, either in combination with statins or as monotherapy, with significantly greater lipid lowering compared with placebo or ezetimibe [13-23].

Given the diversity of the patient population with hypercholesterolemia, the primary objectives of this analysis were to evaluate the influence of intrinsic and extrinsic covariates as potential sources of variability in the PK and exposure-response relationships of unbound evolocumab using a population approach, and to quantify the effect of these sources of variability on the pharmacodynamic (PD) response to evolocumab.

\section{Methods}

\section{Clinical studies}

This population PK (popPK) analysis of evolocumab pooled data from 11 clinical studies, the relevant characteristics of which are summarized in Table 1. Additional details of the clinical trials are reported elsewhere $[11,13-23]$.

\section{Bioanalytical assay}

For all clinical studies used in this analysis, unbound evolocumab concentrations in human serum were determined using a validated enzyme-linked immunosorbent assay. Microplate wells coated with a mouse anti-evolocumab monoclonal antibody (clone no. 1.18.1, Amgen Inc.) were used to capture evolocumab from serum. The capture reagent incubation wells were then washed, and standards, quality controls, and samples were pipetted into the wells. Unbound materials were removed by a subsequent wash step. Horseradish peroxidase-labeled mouse anti-evolocumab monoclonal antibody (clone no. 1.46, Amgen Inc.) was added to the wells for detection of the captured evolocumab. After another wash step, a tetramethylbenzidine substrate solution reacted with the peroxide and produced a colorimetric signal that was proportional to the amount of evolocumab bound by the capture reagent. The color development was stopped by addition of $\mathrm{H}_{2} \mathrm{SO}_{4}$, and the optical density signal was measured at $450 \mathrm{~nm}$ with reference to $650 \mathrm{~nm}$. The lower limit of quantification (LLOQ) and upper limit of quantification for the assay was 0.8 and $10 \mu \mathrm{g} / \mathrm{mL}$, respectively.

\section{Software}

PopPK and PK/PD data were analyzed using the nonlinear, mixed-effects modeling software program NONMEM (version 7.2) [24] on the NONMEM High Performance Cluster (NONMEM HPC), which is a suite of scripts, procedures, and services that supports popPK and PK/PD analyses. It consists of NONMEM 7.2, NMQual 8.2.7, Subversion 1.6.11, MPICH 3.0.4, Grid Engine 2011.11p1, Intel FORTRAN 13.0.1, R 3.0.1, RStudio 0.97.551, and Perl 5.18.1 (1800). NONMEM jobs in the NONMEM HPC system are run on a Grid Engine moderated pseudo-cluster of Intel ${ }^{\circledR}$ Xeon ${ }^{\circledR} \mathrm{CPU}$ X5660@ @ $2.80 \mathrm{GHz}$ processors under Red Hat Enterprise Linux 5.8 (Tikanga). Graphical and all other statistical analyses were performed using either TIBCO Spotfire S+ for Windows version 8.2 (TIBCO Software Inc., Palo Alto, CA) or R software 2.10.1 or higher (The R Foundation for Statistical Computing).

\section{PopPK analysis}

Phase 1 and 2 data were used to develop the initial popPK model. A 1-compartment open model with linear and nonlinear elimination pathways from the central compartment (Fig. 1) was parameterized by volume of distribution (V) in the central compartment, linear clearance (CL), and nonlinear clearance $\left(\mathrm{V}_{\max }, \mathrm{k}_{\mathrm{m}}\right)$, and was selected based on preliminary analyses and visualizations of the data [25]. Attempts were made to fit a target-mediated drug disposition model [12] using the quasi steady-state (QSS) approximation of the full target-mediated drug disposition (TMDD) model estimating steady state constant (kss) from the data, but results showed that the model was overparameterized given the sparseness of $\mathrm{PK}$ data available across subjects (Table 1).

Absorption after SC administration was described by a first-order process from the depot compartment to the central compartment. Bioavailability (F) was used to scale IV to SC dosing. Estimates of the absorption rate constant $\left(\mathrm{k}_{\mathrm{a}}\right)$ and $\mathrm{F}$ were fixed from the phase $1 \mathrm{a}$, densely sampled, single-dose data for subsequent modeling activities. In the population PK analysis, we used the Michaelis-Menten (MM) approximation of the full TMDD model. The $\mathrm{km}$ value was estimated from phase 1 and 2 data where a broad 
Table 1 Summary of the studies and data included in the analyses

\begin{tabular}{|c|c|c|c|c|c|}
\hline Phase/study & Evolocumab dosing & Study population & $\begin{array}{l}\text { Pharmacokinetic } \\
\text { sampling }\end{array}$ & $\begin{array}{l}\text { Total patients } \\
\text { in study }\end{array}$ & $\begin{array}{l}\text { Total patients in } \\
\text { popPK analysis }\end{array}$ \\
\hline $\begin{array}{l}\text { Phase 1a } \\
20080397\end{array}$ & $\begin{array}{l}\text { Single dose: } \\
\text { intravenous: } 21,420 \mathrm{mg} \\
\text { subcutaneous: } 7,21,70,210 \text {, } \\
\quad 420 \mathrm{mg}\end{array}$ & Healthy subjects & Intensive & 56 & 42 \\
\hline $\begin{array}{l}\text { Phase 1b } \\
20080398\end{array}$ & $\begin{array}{l}\text { Multiple dose: } \\
\text { weekly } \times 6 \text { subcutaneous: } 14 \text {, } \\
35 \mathrm{mg} \\
\text { once every } 2 \text { weeks } \times 3 \\
\text { subcutaneous: } 140,280 \mathrm{mg} \\
\text { monthly } \times 3 \text { subcutaneous: } \\
420 \mathrm{mg}\end{array}$ & $\begin{array}{l}\text { Hypercholesterolemia } \\
\text { patients treated with a } \\
\text { statin }\end{array}$ & Intensive & 57 & 43 \\
\hline $\begin{array}{l}\text { Phase } 2 \\
20090158\end{array}$ & $\begin{array}{l}\text { Monthly } \times 3 \text { subcutaneous: } 350 \text {, } \\
420 \mathrm{mg}\end{array}$ & $\begin{array}{l}\text { Combination therapy in } \\
\text { heterozygous familial } \\
\text { hypercholesterolemia } \\
\text { patients }\end{array}$ & $\begin{array}{l}\text { Trough and PK } \\
\text { substudy }\end{array}$ & 167 & 108 \\
\hline $\begin{array}{l}\text { Phase } 2 \\
20090159\end{array}$ & $\begin{array}{l}\text { Monthly } \times 3 \text { subcutaneous: } 280 \text {, } \\
350,420 \mathrm{mg}\end{array}$ & $\begin{array}{l}\text { Combination therapy in } \\
\text { statin-intolerant patients }\end{array}$ & $\begin{array}{l}\text { Trough and PK } \\
\text { substudy }\end{array}$ & 157 & 120 \\
\hline $\begin{array}{l}\text { Phase } 2 \\
20101154\end{array}$ & $\begin{array}{l}\text { Once every } 2 \text { weeks } \times 6 \\
\text { subcutaneous: } 70,105,140 \mathrm{mg} \\
\text { monthly } \times 3 \text { subcutaneous: } 280 \text {, } \\
350,420 \mathrm{mg}\end{array}$ & $\begin{array}{l}\text { Monotherapy in } \\
\text { hypercholesterolemia } \\
\text { patients }\end{array}$ & $\begin{array}{l}\text { Trough and PK } \\
\text { substudy }\end{array}$ & 361 & 269 \\
\hline $\begin{array}{l}\text { Phase } 2 \\
20101155\end{array}$ & $\begin{array}{l}\text { Once every } 2 \text { weeks } \times 6 \\
\text { subcutaneous: } 70,105,140 \mathrm{mg} \\
\text { monthly } \times 3 \text { subcutaneous: } 280 \text {, } \\
350,420 \mathrm{mg}\end{array}$ & $\begin{array}{l}\text { Combination therapy in } \\
\text { hypercholesterolemia } \\
\text { patients }\end{array}$ & $\begin{array}{l}\text { Trough and PK } \\
\text { substudy }\end{array}$ & 629 & 463 \\
\hline $\begin{array}{l}\text { Phase } 3 \\
20110109\end{array}$ & $\begin{array}{l}\text { Monthly } \times 12 \text { subcutaneous: } \\
420 \mathrm{mg}\end{array}$ & $\begin{array}{l}\text { Effect durability in } \\
\text { hypercholesterolemia } \\
\text { patients: monotherapy or } \\
\text { combination therapy }\end{array}$ & Sparse & 901 & 598 \\
\hline $\begin{array}{l}\text { Phase } 3 \\
20110114\end{array}$ & $\begin{array}{l}\text { Once every } 2 \text { weeks } \times 6 \\
\text { subcutaneous: } 140 \mathrm{mg} \\
\text { monthly } \times 3 \text { subcutaneous: } \\
420 \mathrm{mg}\end{array}$ & $\begin{array}{l}\text { Monotherapy in } \\
\text { hypercholesterolemia } \\
\text { patients }\end{array}$ & Sparse & 614 & 293 \\
\hline $\begin{array}{l}\text { Phase } 3 \\
20110115\end{array}$ & $\begin{array}{l}\text { Once every } 2 \text { weeks } \times 6 \\
\text { subcutaneous: } 140 \mathrm{mg} \\
\text { monthly } \times 3 \text { subcutaneous: } \\
420 \mathrm{mg}\end{array}$ & $\begin{array}{l}\text { Combination therapy in } \\
\text { hypercholesterolemia } \\
\text { patients }\end{array}$ & Sparse & 1896 & 1081 \\
\hline $\begin{array}{l}\text { Phase } 3 \\
20110116\end{array}$ & $\begin{array}{l}\text { Once every } 2 \text { weeks } \times 6 \\
\text { subcutaneous: } 140 \mathrm{mg} \\
\text { monthly } \times 3 \text { subcutaneous: } \\
420 \mathrm{mg}\end{array}$ & $\begin{array}{l}\text { Combination therapy in } \\
\text { statin-intolerant patients }\end{array}$ & Sparse & 307 & 187 \\
\hline $\begin{array}{l}\text { Phase } 3 \\
20110117\end{array}$ & $\begin{array}{l}\text { Once every } 2 \text { weeks } \times 6 \\
\text { subcutaneous: } 140 \mathrm{mg} \\
\text { monthly } \times 3 \text { subcutaneous: } \\
420 \mathrm{mg}\end{array}$ & $\begin{array}{l}\text { Combination therapy in } \\
\text { heterozygous familial } \\
\text { hypercholesterolemia } \\
\text { patients }\end{array}$ & Sparse & 329 & 210 \\
\hline
\end{tabular}

Analyses were based on pooled data from 5474 patients, including 3414 who received evolocumab and were included in the final popPK analysis and 1312 from 4 phase 2 studies who were included in the exposure-response analysis

dose range was studied $(70,105$, and $140 \mathrm{mg}$ every 2 weeks [Q2W] and 280, 350, and $420 \mathrm{mg}$ once monthly [QM]), enabling a robust estimate of $\mathrm{km}$. Phase 3 studies evaluated optimal doses selected from phase 2 (140 mg
Q2W and $420 \mathrm{mg}$ QM). The inclusion of 2 doses required fixing $\mathrm{km}$ because the extent of nonlinearity is less evident at these high doses. The MM approximation of the full TMDD model is appropriate to describe the system when 


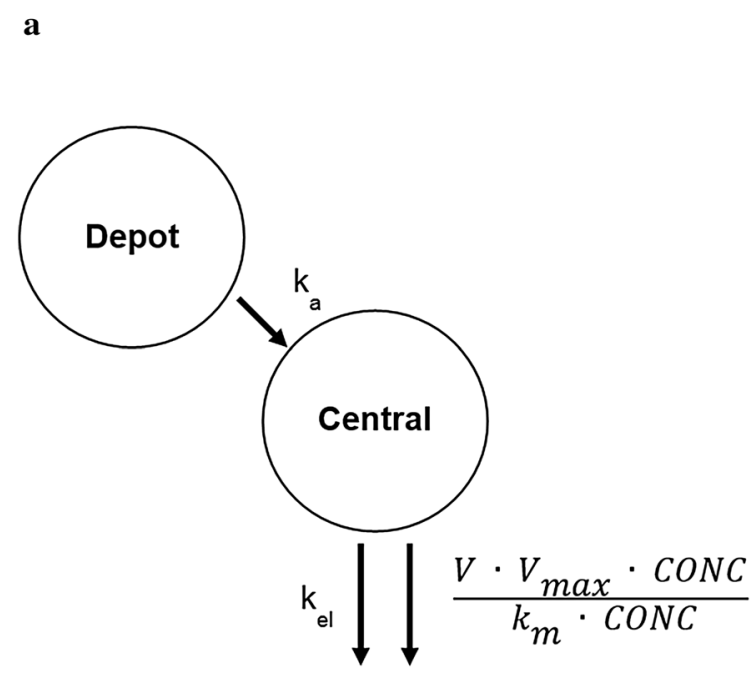

Fig. 1 Evolocumab pharmacokinetic and exposure-response model. a Pharmacokinetic model; $k_{a}$ absorption rate constant; $k_{e l}$ elimination rate constant; $k_{m}$ concentration of half-maximal nonlinear clearance; $V_{\max }$ nonlinear clearance capacity. b Exposure-response model; Eff LDL-C lowering effect; $E_{\max }$ theoretical maximum evolocumab

target concentrations are small relative to the free drug concentrations [25].

Stochastic Approximation Expectation Maximization (SAEM) and Monte Carlo Importance Sampling (IMP) methods [26] were used for structural model development. The SAEM method was conducted in 2 phases: i) burn-in phase until convergence criteria based on evaluation of objective function, thetas, sigmas, and all omega elements were achieved, followed by ii) accumulation phase. The IMP method was evaluated for the purpose of obtaining standard error estimates for each parameter and ensuring stability across independent fits to the model.

Because approximately $19 \%$ of the serum free evolocumab data were below the LLOQ, the M3 method [27-29] was used to analyze serum concentrations below LLOQ.

The between-subject variability (BSV) in the model parameters was assumed to follow a log-normal distribution. BSV was implemented as a full-block variance matrix for random effects on all parameters except for $\mathrm{k}_{\mathrm{a}}$ and $\mathrm{k}_{\mathrm{m}}$, as these 2 parameters were fixed from previous steps. The residual variability of the PK model was assumed to have both additive and proportional components.

In the first step, covariates were evaluated univariately. As discussed in the literature [30], statistical significance does not necessarily predict clinical importance; instead, inferences about clinical importance driven by estimated magnitude of effect and associated precision may be more appropriate. Using a similar approach [30], during univariate covariate analysis, point estimates for covariate effects were estimated for each covariate. Covariates were considered significant if the $95 \%$ confidence interval (CI)

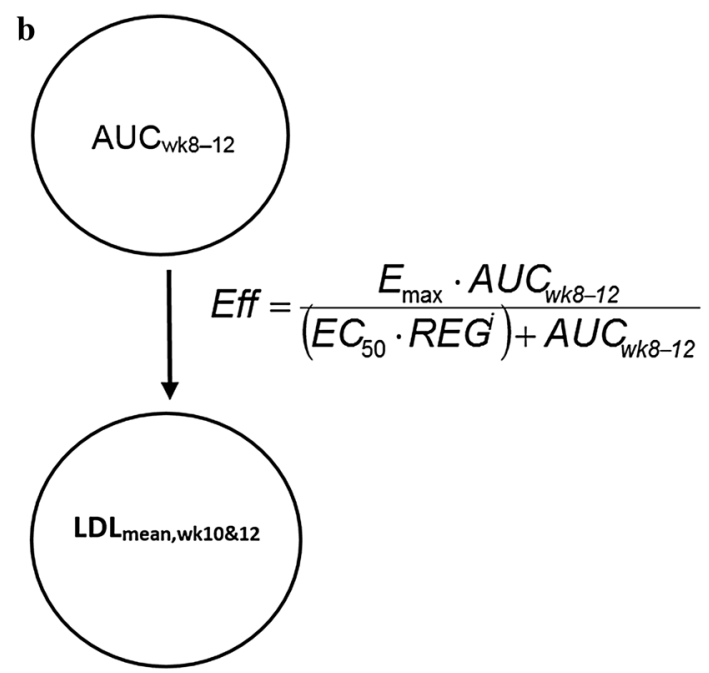

response for the average of weeks 10 and $12 ; E C_{50}((\mu \mathrm{g} / \mathrm{mL}) *$ day $)$ $\mathrm{AUC}_{\mathrm{wk} 8-12}(\mathrm{Q} 2 \mathrm{~W})$ to achieve half-maximal response; $R E G$ regimen effect on $\mathrm{EC}_{50}$ with an indicator variable, $i$, with values of 0 or 1 was used indicate $\mathrm{Q} 2 \mathrm{~W}$ or $\mathrm{QM}$ regimens

of the point estimate of covariate effect did not include 0 for continuous covariates or did not include 1 for categorical covariates. The $95 \%$ CI was calculated based on the standard error estimates following the IMP step. Given the stochastic nature of the SAEM and IMP methods, the change in objective function could not be used as statistical significance criteria for covariate inclusion and exclusion. If the covariate in the univariate analysis was found to be significant based on the above criterion, then the covariate was included in the model with its estimated effect fixed from that step. This step was continued for the rest of the covariates univariately on top of the existing significant covariates in the model, until a full model was obtained. A final model including all significant covariates in the model building process allowing all covariate estimates to be estimated at the final step was used to account for any interacting effects. This final model was used for all simulation and prediction.

Continuous covariates were modeled according to the general equation:

$\mathrm{P}_{j}=T V P \cdot\left(\frac{\operatorname{cov}_{j}}{\operatorname{cov}}\right)^{\Theta} \cdot \exp \left(\eta_{j}\right)$

Categorical covariates were modeled according to the general equation:

$\mathrm{P}_{j}=T V P \cdot \Theta^{\mathrm{cov}_{\mathrm{j}}} \cdot \exp \left(\eta_{j}\right)$

where $\mathrm{P}_{j}$ is the individual model parameter for the $\mathrm{jth}$ subject, TVP is the typical value of the model parameter $\mathrm{P}$, $\operatorname{cov}_{j}$ is the individual's value of the covariate, cov is the population median value of the covariate, $\Theta$ is the magnitude of the covariate effect, and $\eta_{j}$ is an independent and 
normally distributed random variable with mean 0 and variance $\omega^{2}$.

Covariates of interest included demographic parameters (body weight, sex, age, and race), concomitant medications (statins and ezetimibe), laboratory variables (baseline PCSK9), and disease state (heterozygous familial hypercholesterolemia $[\mathrm{HeFH}]$ and renal function). Of the race groups, only the African American group contained enough individuals to estimate covariate effects. The statin covariate represents patients on a statin only and no other comedication because statin comedication was a particular covariate of interest. The ezetimibe covariate includes all patients on ezetimibe, regardless of comedications. The dataset did not include enough patients on ezetimibe alone $(<3 \%)$ for an accurate measurement of the independent effect. For the PK model, any duration of administration of comedication was considered a covariate. Though for monoclonal antibodies renal elimination may be unlikely, potential changes in PK due to varying extents of renal impairment is a critical piece of information for the label. Therefore, a population PK approach similar to that performed for other monoclonal antibodies [31-33] was undertaken to rule out any possibilities of renal effect. The effect of renal function on PK was evaluated using both Cockcroft-Gault creatinine clearance (CrCL) and the Modification of Diet in Renal Disease (MDRD) measures. Across 26 placebo-controlled and active-controlled clinical trials, $0.1 \%$ of patients treated with at least one dose of evolocumab tested positive for binding antibody development. None of these patients tested positive for neutralizing antibodies. There was no evidence that anti-drug binding antibodies affected the PK profile, clinical response, or safety of evolocumab. Therefore, the incidence of antievolocumab binding antibodies is low, and not deemed necessary to evaluate in this analysis [34]. In addition, various analyses showed that evolocumab produced similar lipid-lowering effects in patients with and without diabetes, and hence not deemed a clinically relevant covariate in this analysis [35-37]. Albumin range was expected to be narrow for this population, hence not formally evaluated as a covariate. All covariates evaluated were baseline only.

When evaluating categorical effects, in order to ensure an adequate number of patients per category, categorical covariates with $5 \%$ or greater prevalence in the population data set of phase 1 and 2 data were evaluated for covariate effects. Of the race groups, only the African American group contained more than $5 \%$ of the population dataset to attempt to estimate covariate effects against a reference White patient. The ezetimibe covariate included all patients taking ezetimibe, regardless of lipid-lowering concomitant medications. Of 148 patients taking ezetimibe in the phase 1 and 2 PK model, 117 (79\%) were also taking a statin. Thus, the ezetimibe covariate most generally represented a combination therapy covariate (hereafter notated as statin + ezetimibe). Patients with missing body weight, $\mathrm{CrCL}$, or MDRD values were imputed to the mean values, and patients with missing baseline PCSK9 concentrations were excluded from analyses that included baseline PCSK9 as a covariate. The effect of each demographic and renal function covariate was estimated against $\mathrm{CL}, \mathrm{V}$, and $\mathrm{V}_{\max }$, and the concomitant medications, laboratory variables, and $\mathrm{HeFH}$ were estimated against $\mathrm{V}_{\max }$ due to their possible relationships to unbound PCSK9 concentrations $[8,19,38]$.

Finally, data from 5 phase 3 studies were used to update the popPK model. The observed phase 3 data were overlaid on the model predictions from the phase 1 and 2 model to ensure that no major differences were evident between the phase 3 PK data and the phase 1 and 2 PK data. Because of the sparseness of the phase 3 data and the use of only 2 dosing regimens in phase 3 , estimates of $\mathrm{V}_{\max }$ and $\mathrm{k}_{\mathrm{m}}$ were fixed to the phase 1 and 2 model parameter estimates. Similarly, additional covariates were not tested due to the sparseness of the data and potential for shrinkage [39]. Of 404 patients taking ezetimibe in the final PK model, 377 (93\%) were also taking a statin; thus, the ezetimibe covariate continued to most generally represent a statin + ezetimibe combination therapy covariate.

\section{Exposure-response analysis}

The longitudinal PK/PD relationship in an indirect response model using results from Phase $1 \mathrm{a}$ and $1 \mathrm{~b}$ studies has been reported elsewhere [12]. In phase 2 and phase 3 studies, the primary efficacy endpoint was the mean of weeks 10 and 12 and week 12 LDL-C reduction. The exposure-response analysis based on the primary endpoints was best described by an Emax model, rather than the longitudinal response, which would be best described by the indirect response model. Hence, a week 8-12 exposure-response model was used to characterize the relationship between evolocumab exposure and LDL-C at the mean of weeks 10 and $12\left(\mathrm{LDL}_{\text {mean,wk10\&12) for combined }}\right.$ data from all the phase 2 studies. $\mathrm{LDL}_{\text {mean,wk10\&12 was a }}$ surrogate for the time-averaged effect (TAE) on LDL-C over weeks 8-12. It represented a time-averaged LDL-C reduction over the dosing interval and a comparable measure across dosing regimens Q2W or QM. Further, the absolute LDL-C values were measured clinically and are considered the raw data collected from the studies. We confirmed the appropriateness of the model by transforming the data to \% change from baseline and evaluating diagnostic plots of DV vs PRED, and WRES vs PRED. Evolocumab area under the concentration-time curve from week 8 to $12\left(\mathrm{AUC}_{\mathrm{wk} 8-12}\right)$ was used as the exposure metric, because this represented exposure at steady state during the same time period that the response variable was assessed. 
$\mathrm{AUC}_{\mathrm{wk} 8-12}$ for each patient in the phase 2 studies was predicted from the individual parameter estimates from the phase 1 and $2 \mathrm{PK}$ model. Using the predicted $\mathrm{AUC}_{\mathrm{wk} 8-12}$ eliminated the residual error in the PK, which is a key assumption in the predictor variable for exposure-response relationships. Placebo response was evaluated but was not included in the model, because it was found to be negligible and did not influence the model parameters. The modeled data included the observed predose (days -13 and

0) LDL-C measurements and $\mathrm{LDL}_{\text {mean,wk10\&12. }}$

The model took the form:

$E f f=\frac{E_{\max } \cdot A U C_{w k 8-12}}{\left(E C_{50} \cdot R E G^{i}\right)+A U C_{w k 8-12}}$

Both (1) additive and (2) proportional-effect models were tested to relate the effect size to the baseline of LDLC:

$Y=B A S L+E f f$

$Y=B A S L \cdot(1+E f f)$

where $\mathrm{Y}$ is the predicted response for any $\mathrm{AUC}_{\mathrm{wk} 8-12}$, BASL $(\mathrm{mg} / \mathrm{dL})$ is the baseline LDL-C concentration informed by the predose LDL-C measurements, $\mathrm{E}_{\max }(\mathrm{mg} /$ $\mathrm{dL}$ or a unit-less fraction) is the theoretical maximum evolocumab response for the mean of weeks 10 and 12 , $\mathrm{EC}_{50}$ is the $\mathrm{AUC}_{\mathrm{wk} 8-12}$ required to achieve half-maximal response with evolocumab dosed Q2W, and Eff is the effect magnitude. A regimen effect (REG) was modeled as a multiplier on $\mathrm{EC}_{50}$ to account for the dosing interval differences between the Q2W and QM regimens. An indicator variable, $i$, with a value of 0 or 1 , was used to indicate Q2W or QM regimens, respectively. If the $95 \% \mathrm{CI}$ of the REG multiplier included 1 , the $\mathrm{EC}_{50}$ of the $\mathrm{QM}$ regimen did not differ significantly from the Q2W regimen. This way, we could assess if regimen would have any impact on efficacy. The different $\mathrm{EC}_{50}$ values are a result of the difference in the time courses of target saturation between the dosing regimens, given the lack of kinetics in the exposure-response $\mathrm{E}_{\max }$ model. A random effect on the baseline was included in the model assuming a log-normal distribution. Additive, proportional, and combined additive and proportional error models were considered to describe the residual variability. Data were fit using first-order conditional estimation method with interaction (FOCEI) followed by an IMP step for the purpose of obtaining standard error estimates for each parameter. A placebo effect was tested on Y.

Covariates of interest included concomitant medications (statins and ezetimibe), disease (diabetes and $\mathrm{HeFH}$ ), and laboratory variables (baseline PCSK9). For the exposureresponse model, only stable concomitant medication (> 4 weeks of administration before study day 1) was considered a covariate to ensure an accurate estimation of the effects of baseline concomitant medication use. The statin covariate represented patients taking only a statin and no other concomitant medication. The ezetimibe covariate included all patients taking ezetimibe, regardless of concomitant medications. Of 160 patients taking ezetimibe in the exposure-response model, 158 (99\%) were also taking a statin; thus, the ezetimibe covariate most generally represented a combination therapy covariate. Patients with missing baseline PCSK9 concentrations were excluded from analyses that included baseline PCSK9 as a covariate. Concomitant medications and $\mathrm{HeFH}$ were estimated against both the baseline LDL-C concentration and Eff, and diabetes and laboratory variables were modeled against Eff.

Finally, the observed phase 3 data were overlaid on the model predictions from the phase 1 and 2 model to ensure that no major differences were evident between the phase 3 response data and the phase 1 and 2 response data. Because of the sparseness of the phase 3 data and the use of only 2 dosing regimens in phase 3 , possibly leading to increased shrinkage in the updated PK model, the exposure-response model was not updated with data from phase 3. Similarly, additional covariates were not tested due to the sparseness of the data and potential for shrinkage. No liabilities in the results are anticipated as the patient population was similar between phase 2 and phase 3 studies; hence, it is not expected that inclusion of additional patients from phase 3 would lead to identification of any additional covariates.

For comparisons of outcomes across significant covariates, an $84 \mathrm{~kg}$ male patient (mean weight of the patients in this analysis) with hypercholesterolemia, not taking other lipid-lowering medications and with baseline PCSK9 of $5.9 \mathrm{nM}(425 \mathrm{ng} / \mathrm{mL})$, was considered as the reference patient.

\section{Model-based simulation}

Forest plots were generated based on the simulated parameter, incorporating the uncertainty for each significant covariate condition on the final covariate models. Parameter sets for 1000 individuals were constructed based on the variance-covariance structure for the thetas of the final covariate models using the simpar function built into the NONMEM HPC [40]. These simulations did not include BSV or residual variability. Outcomes of interest for each individual, $\mathrm{AUC}_{\mathrm{wk} 8-12}$ and $\mathrm{LDL}_{\text {mean,wk10\&12, were }}$ simulated under the significant covariate conditions of the final covariate models. Thus, the outcome for each individual under a covariate condition could be compared to the "same" individual in the reference (e.g., without the covariate condition). In this way, the geometric mean of the change in outcome relative to baseline for each covariate condition could be calculated across 1000 individuals. 
These were plotted along with the $95 \% \mathrm{CI}$ of the geometric mean [41].

\section{Results}

The final dataset was pooled from 5474 patients across phase 1,2 , and 3 studies to represent the intended target population. Of these patients, 3414 receiving evolocumab were included in the popPK analysis, and 1314 patients across 4 phase 2 studies were included in the exposure- response analysis. The popPK analysis dataset contained 16,179 evolocumab concentrations. Table 2 shows patient baseline characteristics.

A 1-compartment model with linear and nonlinear elimination pathways characterized the $\mathrm{PK}$ of unbound evolocumab after IV and SC dosing (Fig. 1). In the covariate analysis based on data from phase 1 and 2 studies, body weight, female sex, concomitant use of a statin, concomitant use of statin + ezetimibe, and baseline PCSK9 concentration emerged as statistically significant covariates on unbound evolocumab PK. With the inclusion

Table 2 Patient characteristics

\begin{tabular}{|c|c|c|c|}
\hline Covariate & Category & $\begin{array}{l}\text { Phase } 1 \text { and } 2 \\
(\mathrm{~N}=1045)\end{array}$ & $\begin{array}{l}\text { Phase } 1,2 \text {, and } 3 \\
(\mathrm{~N}=3414)\end{array}$ \\
\hline \multirow[t]{2}{*}{ Age, years } & Mean (standard deviation) & $56(58)$ & $57(58)$ \\
\hline & [range] & {$[18-80]$} & [18-80] \\
\hline \multirow[t]{2}{*}{ Body weight, $\mathrm{kg}$} & Mean (standard deviation) & $84.2(82)$ & $84.2(83)$ \\
\hline & [range] & {$[42-173]$} & {$[41-175]$} \\
\hline \multirow{2}{*}{$\begin{array}{l}\text { Baseline proprotein convertase subtilisin/kexin } \\
\text { type } 9, \mathrm{ng} / \mathrm{mL}\end{array}$} & Mean (standard deviation) & $433(409)$ & $402(375)$ \\
\hline & [range] & {$[150-1233]$} & {$[15.5-1233]$} \\
\hline \multirow[t]{2}{*}{ Baseline albumin, g/dL } & Mean (standard deviation) & $4.0(0.3)$ & $4.3(0.4)$ \\
\hline & [range] & {$[2.6-5.6]$} & {$[2.6-5.6]$} \\
\hline \multirow[t]{2}{*}{ Sex, n (\%) } & Male & $488(47)$ & $1708(50)$ \\
\hline & Female & $557(53)$ & $1706(50)$ \\
\hline \multirow[t]{8}{*}{ Statin therapy, n (\%) } & None & $415(40)$ & $938(28)$ \\
\hline & Atorvastatin & $160(15)$ & $1170(34)$ \\
\hline & Rosuvastatin & $172(17)$ & $731(21)$ \\
\hline & Simvastatin & $244(23)$ & $497(15)$ \\
\hline & Lovastatin & $11(1)$ & $12(0)$ \\
\hline & Pravastatin & $32(3)$ & $41(1)$ \\
\hline & Pitavastatin & $1(0)$ & $3(0)$ \\
\hline & Fluvastatin & $8(1)$ & $13(0)$ \\
\hline \multirow[t]{6}{*}{ Concomitant medication, n (\%) } & Ezetimibe & $143(14)$ & $404(12)$ \\
\hline & Omega-3 fatty acid & $35(3)$ & $159(5)$ \\
\hline & Bile acid sequestrants & $3(0)$ & $29(1)$ \\
\hline & Other lipid-lowering therapy & $4(0)$ & $8(0)$ \\
\hline & Niacin & $1(0)$ & $8(0)$ \\
\hline & Fibrates & $1(0)$ & $2(0)$ \\
\hline \multirow[t]{2}{*}{ Disease state, $\mathrm{n}(\%)$} & Diabetes & $108(10)$ & $386(11)$ \\
\hline & $\begin{array}{l}\text { Heterozygous familial } \\
\text { hypercholesterolemia }\end{array}$ & $108(10)$ & $318(9)$ \\
\hline \multirow[t]{8}{*}{ Race/ethnicity, n (\%) } & White or Caucasian & $885(85)$ & $2984(87)$ \\
\hline & Black or African American & $96(9)$ & $222(7)$ \\
\hline & Hispanic or Latino & $11(1)$ & $11(0)$ \\
\hline & Asian & $34(3)$ & $129(4)$ \\
\hline & American Indian or Alaska native & $5(0)$ & $10(0)$ \\
\hline & $\begin{array}{l}\text { Native Hawaiian or other Pacific } \\
\text { Islander }\end{array}$ & $5(0)$ & $8(0)$ \\
\hline & Other & $9(1)$ & $47(1)$ \\
\hline & Multiple & $0(0)$ & $3(0)$ \\
\hline
\end{tabular}


Table 3 Parameter estimates for population pharmacokinetics model

\begin{tabular}{|c|c|c|c|c|}
\hline Parameter (definition) & Units & $\begin{array}{l}\text { Estimate (\% relative } \\
\text { standard error) }\end{array}$ & $\begin{array}{l}\text { Between subject variability } \\
\text { (\% relative standard error) }\end{array}$ & Shrinkage \\
\hline F (subcutaneous bioavailability) & $\%$ & 0.72 (FIXED) & $0 \%$ & - \\
\hline $\mathrm{k}_{\mathrm{a}}$ (absorption rate constant) & day $^{-1}$ & 0.319 (FIXED) & $74.6 \%$ (FIXED) & $48.4 \%$ \\
\hline CL (linear clearance) & L/day & $0.105(2.18 \%)$ & $54.3 \%(3.20 \%)$ & $47.6 \%$ \\
\hline Body weight exponent & & $0.276(30.4 \%)$ & & \\
\hline $\mathrm{V}$ (volume of distribution) & $\mathrm{L}$ & $5.18(1.15 \%)$ & $28.3 \%(3.27 \%)$ & $25.2 \%$ \\
\hline Body weight exponent & & $1.04(4.05 \%)$ & & \\
\hline Female exponent & & $1.11(1.42 \%)$ & & \\
\hline $\mathrm{V}_{\max }($ nonlinear clearance capacity) & $\mathrm{nM} /$ day & 9.85 (FIXED) & $31.1 \%(3.54 \%)$ & $43.8 \%$ \\
\hline Body weight exponent & & $0.145(33.0 \%)$ & & \\
\hline Statin exponent & & $1.13(1.02 \%)$ & & \\
\hline Statin + ezetimibe exponent & & $1.20(1.59 \%)$ & & \\
\hline PCSK9 baseline exponent & & $0.194(7.47 \%)$ & & \\
\hline $\mathrm{k}_{\mathrm{m}}$ (concentration of half-maximal nonlinear clearance) & $\mathrm{nM}$ & 27.3 (FIXED) & $0 \%$ (FIXED) & - \\
\hline Residual proportional error & $\%$ & $0.282(1.12 \%)$ & - & \\
\hline Residual additive error & $\mathrm{nM}$ & $5.41(2.50 \%)$ & - & \\
\hline
\end{tabular}

Table 4 Parameter estimates for exposure-response model

\begin{tabular}{|c|c|c|c|c|}
\hline Parameter & Units & $\begin{array}{l}\text { Estimate }(\% \text { relative } \\
\text { standard error) }\end{array}$ & $\begin{array}{l}\text { Between subject variability } \\
(\% \text { relative standard error })\end{array}$ & Shrinkage \\
\hline Baseline LDL-C & $\mathrm{mg} / \mathrm{dL}$ & $150(0.92 \%)$ & $20.0 \%(2.26 \%)$ & $7.87 \%$ \\
\hline Statin exponent & & 0.797 & & \\
\hline Ezetimibe exponent & & 0.768 & & \\
\hline Heterozygous familial hypercholesterolemia exponent & & 1.28 & & \\
\hline $\begin{array}{l}\mathrm{E}_{\max } \text { (maximal change in LDL-C following } \\
\text { evolocumab administration) }\end{array}$ & $\mathrm{mg} / \mathrm{dL}$ & $-99.7(2.17 \%)$ & - & \\
\hline Statin exponent & & 0.937 & & \\
\hline $\begin{array}{l}\mathrm{EC}_{50} \text { (evolocumab exposure resulting } \\
\text { in } 50 \% \text { of maximal effect }\end{array}$ & $(\mu \mathrm{g} / \mathrm{mL}) \cdot \mathrm{day}$ & $51.5(9.79 \%)$ & - & \\
\hline $\begin{array}{l}\text { REG (regimen effect; once monthly relative } \\
\text { to once every } 2 \text { weeks) }\end{array}$ & - & $2.30(10.3 \%)$ & - & \\
\hline Residual proportional error & $\%$ & 0 (FIXED) & - & \\
\hline Residual additive error & $\mathrm{mg} / \mathrm{dL}$ & $19.3(1.35 \%)$ & & \\
\hline
\end{tabular}

of covariates in the popPK model, BSV on $\mathrm{CL}$ and $\mathrm{V}_{\max }$ was reduced (from $87.4 \%$ to $75.5 \%$ and from $73.9 \%$ to $50.4 \%$, respectively), but BSV on V was not reduced (from $28.3 \%$ to $28.1 \%$ ). Statin, statin + ezetimibe, and $\mathrm{HeFH}$ were statistically significant covariates on the exposureresponse relationship. The statin effect accounted for differences between patients taking or not taking statins. Any influence of high- vs low-intensity statins and their impact on PCSK9 was addressed by including baseline PCSK9 levels in the model.

The updated phase 3 popPK model, including all the significant covariates from the phase 1 and 2 model, fit the data adequately, and parameter estimates were similar to those from the phase 1 and 2 model (Table 3 ). Both structural model parameters and residual variability parameters were estimated with good precision, as measured by a relative standard error (RSE) of $<5 \%$. Covariate effects also were precisely estimated $(\mathrm{RSE}<8 \%$ ), with the exception of the body weight effects on CL and $\mathrm{V}_{\max }$, which were $30.4 \%$ and $33.0 \%$, respectively. The precision of the body weight covariate effects on $C L$ and $V_{\text {max }}$ may have been influenced by the high correlation between individual random effects on CL and $\mathrm{V}_{\text {max }}$ (Table 4). Baseline PCSK9 concentrations ( $\sim 400 \mathrm{ng} / \mathrm{mL}$ ) were small relative to mean observed 

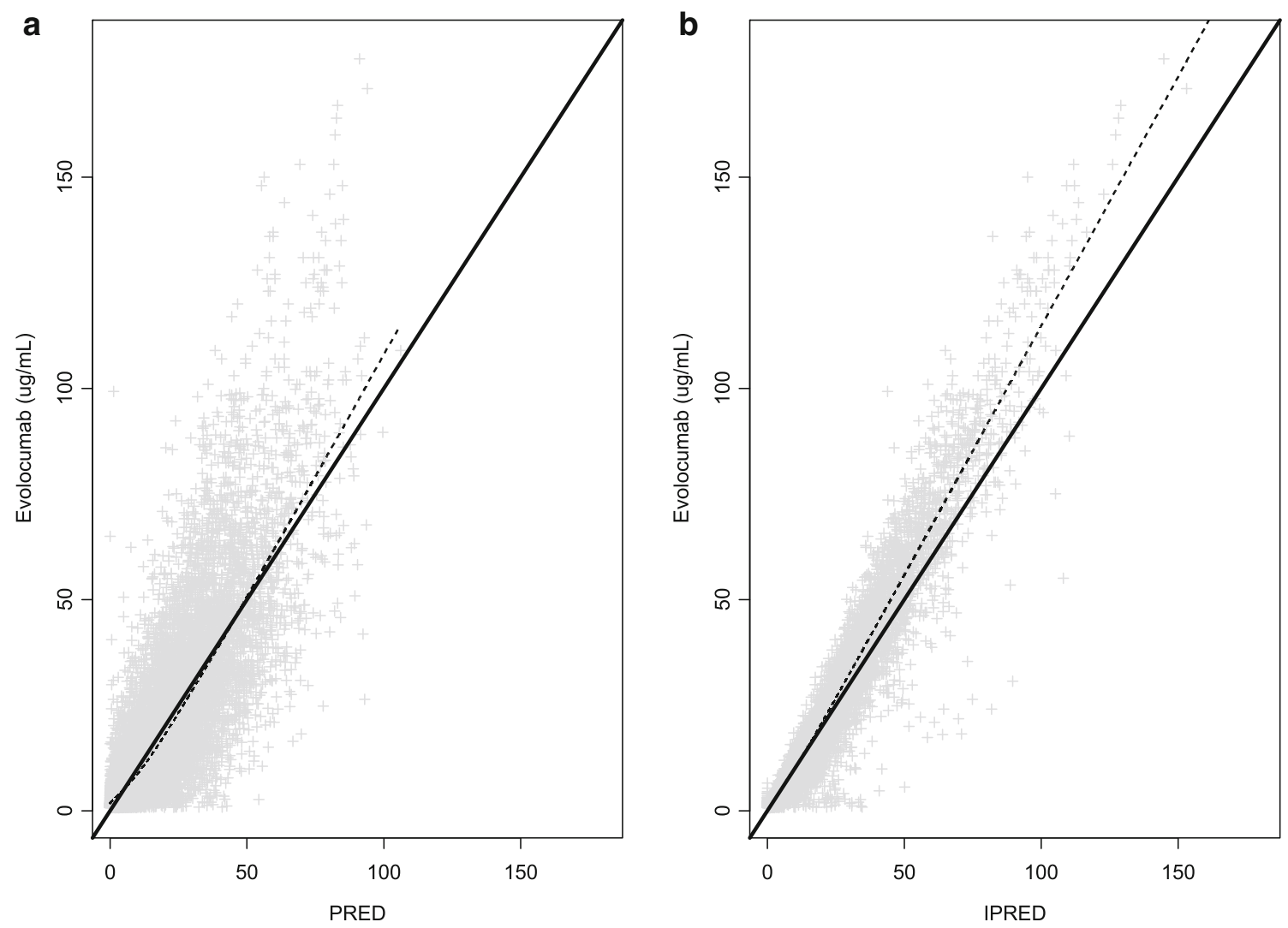

Fig. 2 Observed and model-predicted serum evolocumab concentrations. Solid line: line of unity; dashed line: locally weighted scatterplot smoothing (LOWESS); PRED population predicted concentration; IPRED individual predicted concentration

unbound evolocumab $\mathrm{C}_{\max }$ of 18.6 or $59 \mu \mathrm{g} / \mathrm{mL}$ after $140 \mathrm{mg}$ SC Q2W or $420 \mathrm{mg}$ SC QM, respectively [34]. In the MM TMDD model approximation, $\mathrm{k}_{\mathrm{m}}$ represented the ratio of the sum of the complex internalization rate and dissociation rate constant to the drug-target dissociation rate constant. Because $\mathrm{k}_{\mathrm{m}}$ and $\mathrm{K}_{\mathrm{d}}$ values reflect different processes, it would not be appropriate to fix $\mathrm{k}_{\mathrm{m}}$ to the measured in vitro $K_{d}$. The large differences in $k_{m}$ and in vitro $K_{d}$ most likely reflect impact of rapid elimination of the drug-target complex on the $\mathrm{k}_{\mathrm{m}}$ value. Precision of the diagonal elements of the BSV estimates was good (RSE $<10 \%)$. Goodnessof-fit plots (Fig. 2) and individual model fits (Fig. 3) showed the adequacy of the model to describe the data and the absence of systematic bias. The goodness-of-fit plot for the population PK model suggest that in general, there was a good agreement between the observed and model-predicted evolocumab serum concentrations, although some high concentrations were under-predicted. This is particularly evident in the QM dosing regimens. During the model building process, an attempt was made to use the quasi steady state approximation of the TMDD model. However, due to limited data in the lower dose ranges, the model was over-parametrized, and hence a simpler approach using the MM approximation of TMDD model was adopted. This under-prediction was not considered important as the outcomes of interest for the PK model, $\mathrm{AUC}_{\mathrm{wk} 8-12}$ and the week 12 trough concentration, were well predicted. With the exception of a negligible number of outliers who missed a dose, the week 8-12 AUCs for the available observed data in phase 2 substudy patients are accurately predicted by the model. As noted above, it is possible that use of a $1 \mathrm{cmt}$ model instead of a $2 \mathrm{cmt}$ model produces some bias in the model. However, due to data being mostly subcutaneously administered, this could not be ascertained during model building. Results of the visual predictive checks (Fig. 4) confirmed the ability of the model to describe the timecourse of evolocumab concentrations and its associated variability in the target population. For patients in the phase 2 PK substudies (in which a PK time-course was collected), observed $\mathrm{AUC}_{\mathrm{wk} 8-12}$ was well-predicted by the model, providing another confirmation of the model adequacy. $\mathrm{AUC}_{\mathrm{wk} 8-12}$ was found to be correlated with body weight and sex (Fig. 5).

The exposure-response model characterized observed LDL- $\mathrm{C}_{\text {mean,wk10\&12 }}$ based on the individual predicted $\mathrm{AUC}_{\mathrm{wk} 8-12}$ from the PK model. The additive-effect exposure-response model fit the data and was selected. In the final exposure-response covariate model, concomitant use 


\section{a $140 \mathrm{mg}$ Dose Group PK fit}
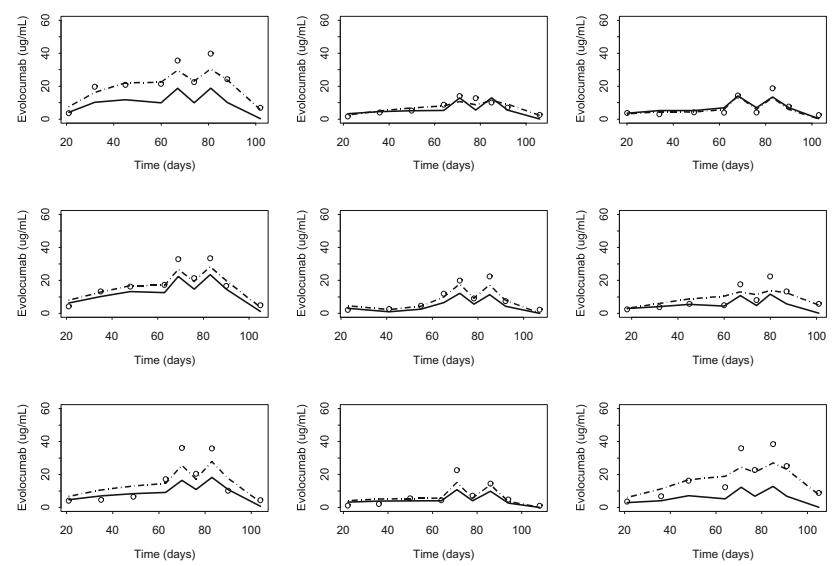

c $140 \mathrm{mg}$ Dose Group PD fit
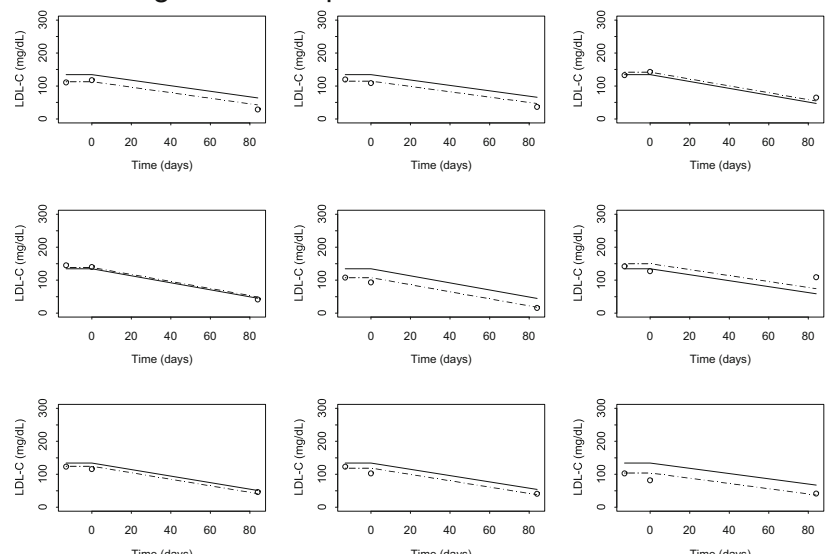

\section{b 420 mg Dose Group PK fit}
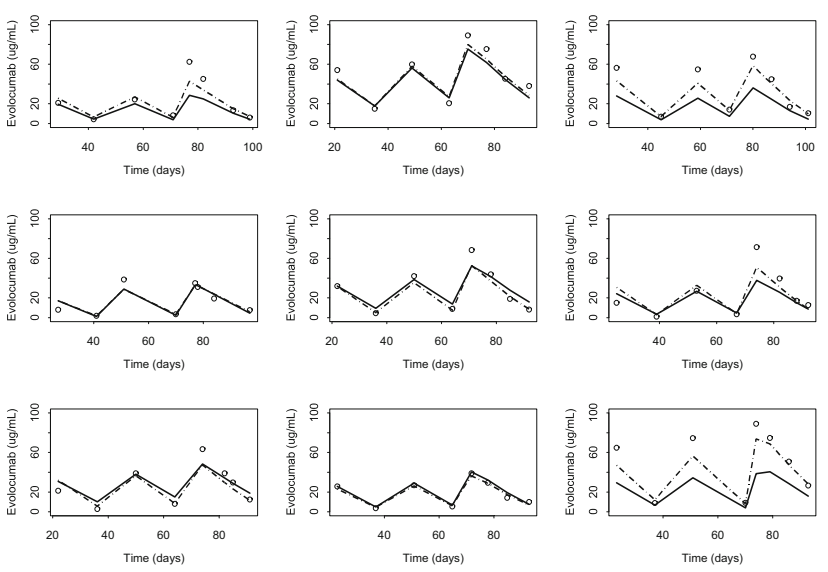

d 420 mg Dose Group PD fit
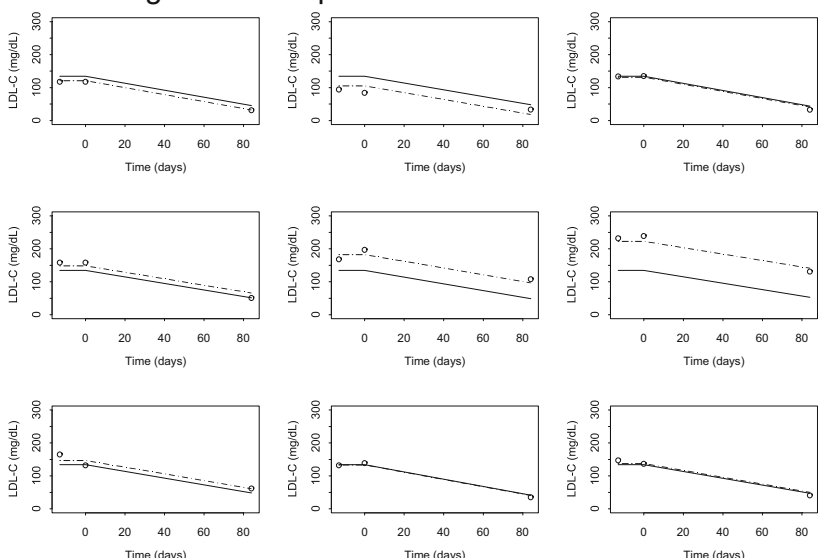

Fig. 3 PK and PD individual model fits for representative patients. Points: observations; solid line: population prediction (PRED); dashed line: individual prediction (IPRED)

of a statin, concomitant use of statin + ezetimibe, and $\mathrm{HeFH}$ emerged as the biggest drivers of change in PCSK9 and evolocumab response (Table 4). Individual model fits of representative patients are shown in Fig. 3. Doses of $140 \mathrm{mg}$ SC Q2W and $420 \mathrm{mg}$ SC QM achieved approximately $80 \%$ of the model-predicted maximal reduction $\mathrm{LDL}_{\text {mean,wk10\&12. }}$. The model-predicted maximal reduction in $\mathrm{LDL}_{\text {mean,wk10\&12 was }} 99.7 \mathrm{mg} / \mathrm{dL}$ from a baseline value of $134 \mathrm{mg} / \mathrm{dL}$, or a $66 \%$ reduction from baseline (Fig. 6). These doses of evolocumab led to a response near the plateau of the exposure-response relationship.

As evident in the PK forest plots (Fig. 7), only body weight at the extremes $(40 \mathrm{~kg}$ and $140 \mathrm{~kg}$ ) seemed to markedly affect $\mathrm{AUC}_{\mathrm{wk} 8-12}$. Concomitant lipid-lowering medications such as statins and statins + ezetimibe showed a modest reduction in $\mathrm{AUC}_{\mathrm{wk} 8-12}$. In the response forest plots (Fig. 8), no covariates appeared to significantly modify evolocumab response. In these plots, a point estimate greater than 1.0 represented a stronger response (higher percentage change from baseline), and a point estimate less than 1.0 represented less of a response. Of note, all the $\mathrm{HeFH}$ patients in the dataset were taking a statin and/or ezetimibe, so simulations for a hypothetical $\mathrm{HeFH}$ patient not on lipid-lowering therapy were included for completeness but are not clinically relevant.

\section{Discussion}

This popPK model was used to evaluate evolocumab PK from data collected during clinical development in phase 1, 2 , and 3 studies. The 1-compartment model with linear and nonlinear elimination pathways was suitable to describe the time-course of serum unbound evolocumab concentrations following IV or SC administration of a single dose or multiple doses once every week, Q2W, or QM ranging from 7 to $420 \mathrm{mg}$ in healthy subjects or patients with hypercholesterolemia. There was no evidence of time-dependent PK for evolocumab. Although the PK of a monoclonal antibody typically is described by a 2-compartment 


\section{a $140 \mathrm{mg}$}

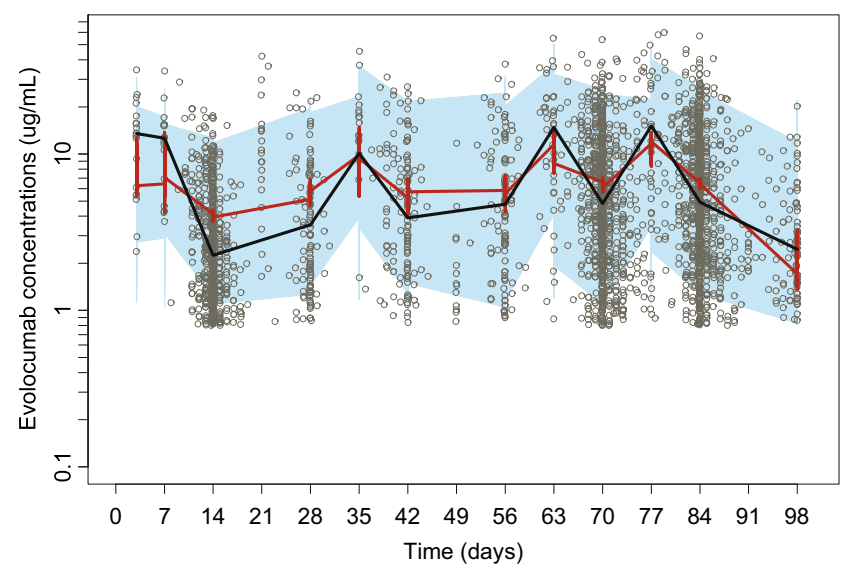

C $420 \mathrm{mg}$ (to week 52)

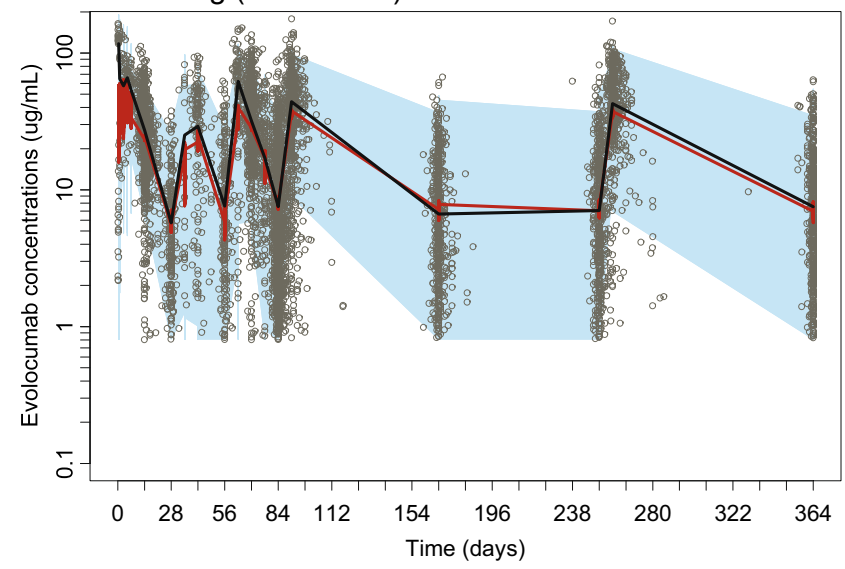

Fig. 4 Time-course of model-predicted and observed serum evolocumab concentrations after doses of $140 \mathrm{mg}$ SC Q2W (6 doses) and $420 \mathrm{mg}$ SC QM (3 doses). Simulations were performed (number of trials $=100$ ) on the entire dataset. Dots: observed evolocumab serum concentrations. Panels a, b, and c: blue shaded area: $90 \%$ prediction interval of simulated evolocumab serum concentration-time profile, and red line is predicted median, whereas black line is observed median. Panel d: The solid red lines represent the 95th (upper red line), 50th (middle red line), and 5th (lower red line) percentiles of the

model [42], a 1-compartment model can be appropriate when the concentration data are mostly available following $\mathrm{SC}$ administration, and a relatively slower absorption phase masks the initial distribution phase of concentration decline that is observed following IV administration [42]. A 1-compartment PK model has been reported for some monoclonal antibodies such as efalizumab [43], golimumab [44], and ustekinumab [45].

Major factors affecting bioavailability of monoclonal antibodies following SC administration may include relative rates of presystemic catabolism and systemic absorption [46, 47]. The absolute bioavailability of evolocumab SC dose was fixed to $72 \%$ based on analysis of phase 1a densely sampled single-dose data, which is consistent with b $420 \mathrm{mg}$ (to week 12)
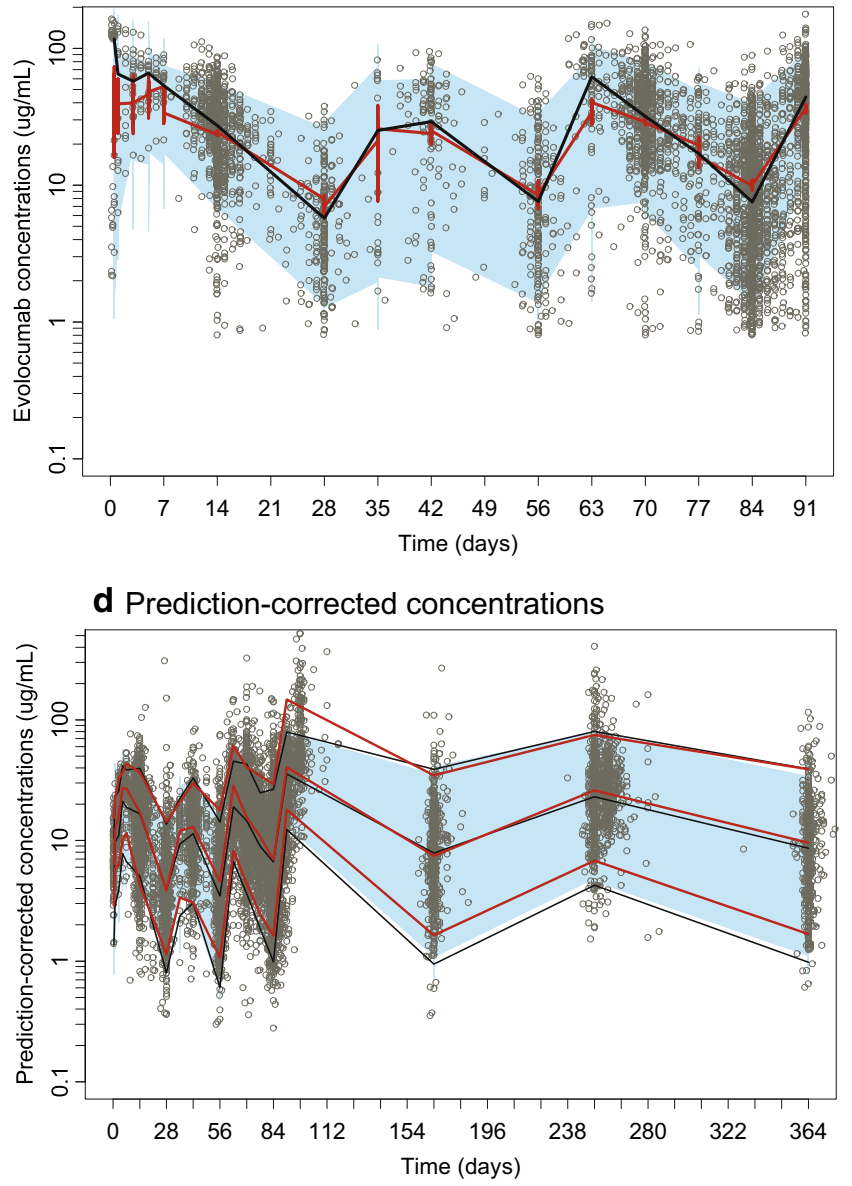

observed prediction-corrected serum concentration. The observed prediction-corrected plasma concentrations are represented by grey circles. The black lines (upper: 95th, middle: 50th, and lower: 5th) represent the simulation-based prediction, and the surrounding semitransparent blue field represents a simulation-based $90 \%$ prediction interval for the corresponding simulation-based prediction intervals. $Q 2 W$ once every 2 weeks; $Q M$ once monthly; $S C$ subcutaneous

the reported values (24-95\%) for other mono-clonal antibodies such as canakinumab, ustekinumab, and omalizumab [46-48].

The mechanisms of distribution of evolocumab are expected to be similar to other monoclonal antibodies. Accordingly, evolocumab typical V (BSV\%) was $5.18 \mathrm{~L}$ $(28 \%)$ and was similar to the values reported for efa-lizumab, basiliximab, and omalizumab [49-51]. Because evolocumab $\mathrm{V}$ is similar to typical plasma volume, this is consistent with a lack of extensive extravascular distribution.

Similar to other monoclonal antibodies [42], evolocumab is eliminated through a nonspecific (linear) pathway via the reticuloendothelial system and a target-mediated (nonlinear) pathway via PCSK9, which was implemented 


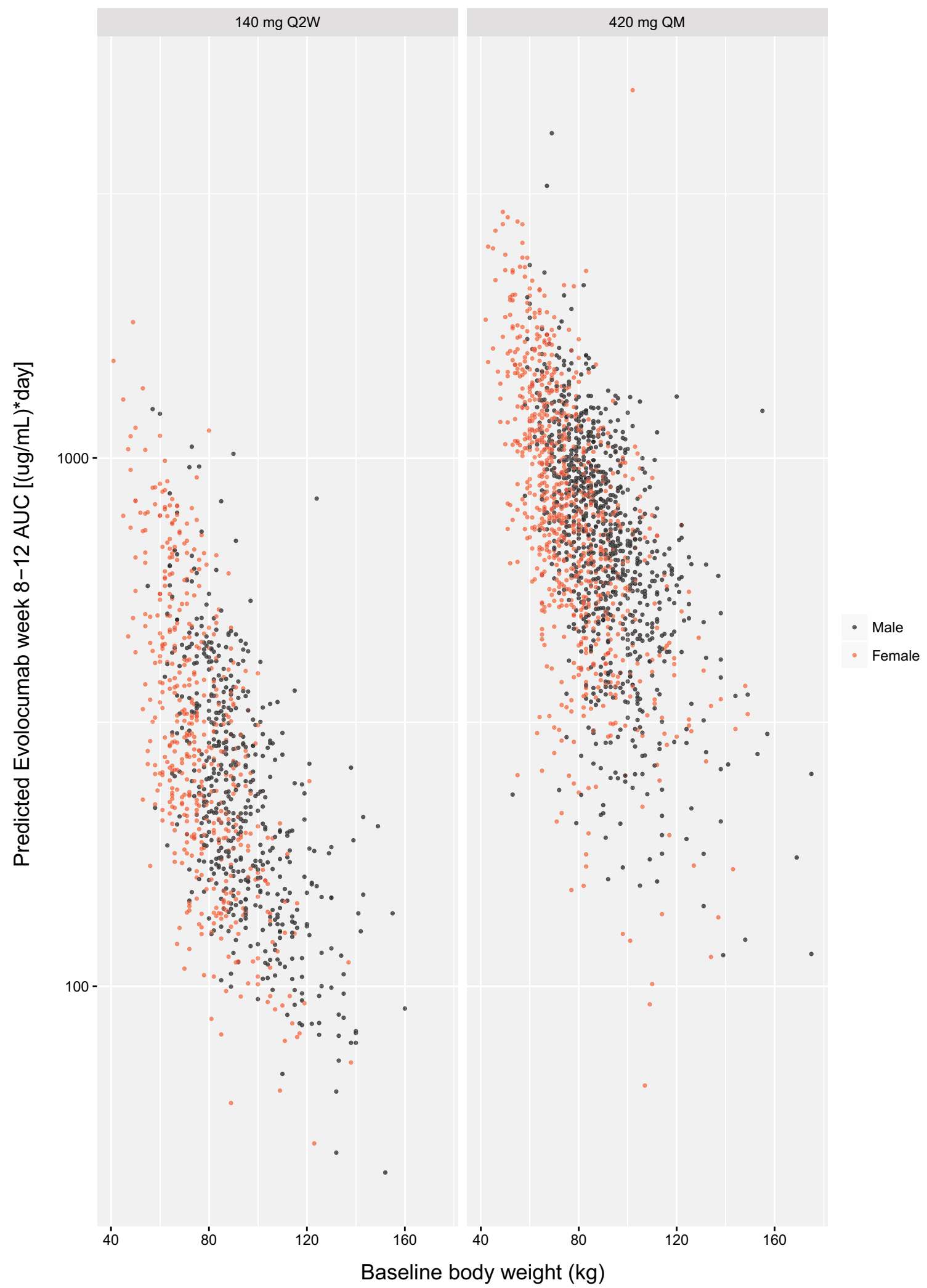

Fig. 5 AUC week $8-12$ versus body weight for all patients by sex 


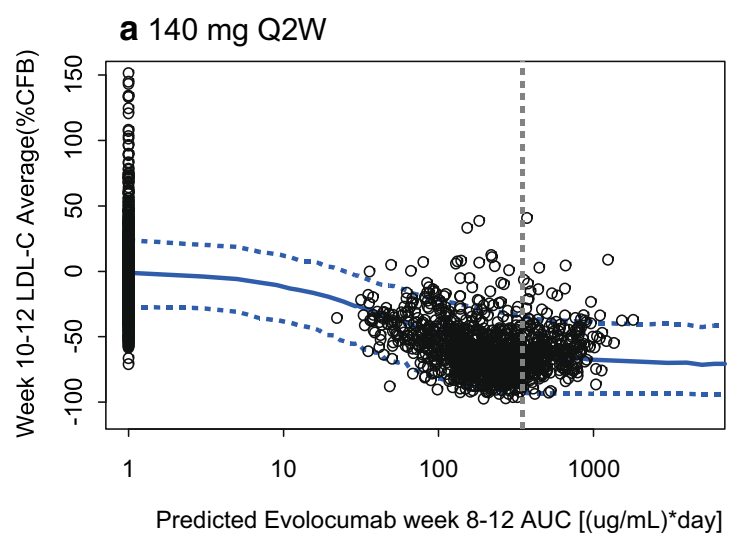

Fig. 6 Observed data and 90\% prediction interval for week 10 and 12 mean calculated LDL-C for phase 2 studies by weeks 8-12 evolocumab-predicted AUC. Prediction of the mean week 10 and 12 calculated LDL-C concentration, in percentage change from baseline, 50th (solid line) and 5th and 95th (dashed lines) percentiles. Simulations were performed for $\mathrm{n}=2000$ patients. Points: observed

in the model as a capacity-limited (i.e., saturable) elimination process. CL was estimated to be $0.105 \mathrm{~L} /$ day, which is within the range of the reported CLs (0.071-0.535 $\mathrm{L} /$ day) of other monoclonal antibodies [42]. The $\mathrm{V}_{\max }$ of $9.85 \mathrm{nM} /$ day is equivalent to $7.7 \mathrm{mg}$ of evolocumab eliminated per day through the nonlinear elimination route. Model predictions suggested that approximately $77 \%$ of evolocumab is eliminated through this nonlinear pathway for a single $140 \mathrm{mg} \mathrm{SC}$ dose, and approximately $51 \%$ for a single $420 \mathrm{mg}$ SC dose. When the dose of evolocumab leads to serum concentrations below $0.4 \mu \mathrm{g} / \mathrm{mL}$ (approximately 10-fold below the $\mathrm{k}_{\mathrm{m}}$ value), the nonlinear (and presumably target-mediated) elimination pathway is unsaturated, and the kinetics behave linearly. We have previously observed a TMDD relationship when simultaneously fitting unbound evolocumab and PCSK9 with the QSS TMDD model [12]. Dose proportional increases in evolocumab exposures were observed at doses greater than or equal to $140 \mathrm{mg}$ SC when PCSK9 suppression was maintained over the dosing interval. Similarly, when the dose of evolocumab leads to serum concentrations above $40 \mu \mathrm{g} / \mathrm{mL}$ (approximately 10-fold above the $\mathrm{k}_{\mathrm{m}}$ value), the proportion of the saturable elimination pathway becomes negligible when compared to the linear pathway, and the elimination kinetics behave linearly in this range as well. When the nonlinear elimination pathway is saturated, model parameters suggest a half-life of approximately 34 days. When the dose of evolocumab (or time-course of the concentration-time profile) leads to serum concentrations between 0.4 and $40 \mu \mathrm{g} / \mathrm{mL}$, both the linear and nonlinear components affect the elimination kinetics. When the dose of evolocumab (or time-course of the concentration-time profile) leads to serum concentrations below $0.4 \mu \mathrm{g} / \mathrm{mL}$, the nonlinear component becomes

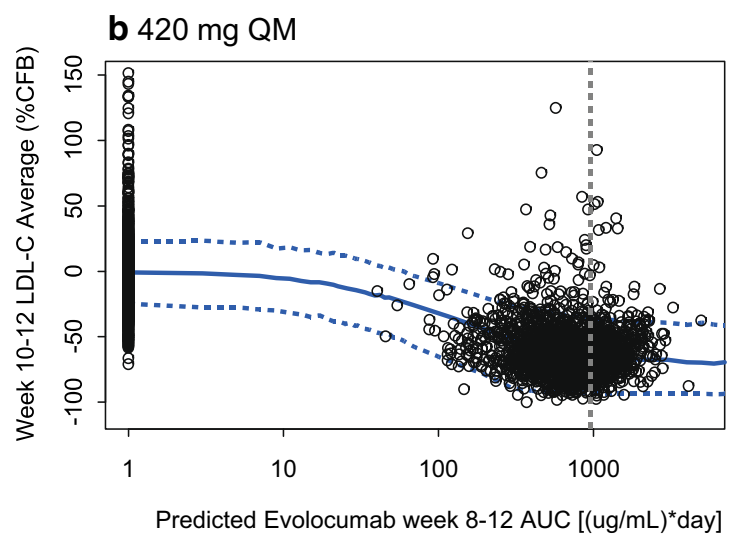

individual mean of weeks 10 and 12 LDL-C measurements. Vertical line: mean observed $\mathrm{AUC}_{\mathrm{wk} 8-12}$ in phase $2 . \% C F B$ percentage change from baseline; $A M G 145$ evolocumab; $A U C$ area under the concentration-time curve; $L D L-C$ low-density lipoprotein-cholesterol; $Q 2 W$ once every 2 weeks; $Q M$ once monthly

predominant, with an elimination half-life of approximately 1.9 days based on the ratio of $\mathrm{V}_{\max }$ and $\mathrm{k}_{\mathrm{m}}$. The model-predicted effective half-life for the clinical doses of $140 \mathrm{mg}$ SC Q2W and $420 \mathrm{mg} \mathrm{SC}$ QM is 11.4 and 16.8 days, respectively, due to a combination of linear and nonlinear elimination pathways.

The exposure-response model showed robust reduction in calculated LDL-C across the evolocumab dose range studied. $\mathrm{AUC}_{\mathrm{wk} 8-12}$ accurately predicted the

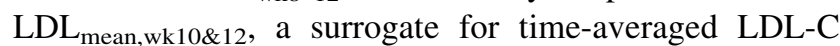
over weeks 8-12. This TAE is a complete measure of the effect of evolocumab and is a comparable measure across dosing regimens when PK and PD steady-state has been achieved. The model-predicted maximal reduction in $\mathrm{LDL}_{\text {mean,wk10\&12 was }} 99.7 \mathrm{mg} / \mathrm{dL}$, or a $66 \%$ change from baseline, with an $\mathrm{EC}_{50}$ of $51.5(\mu \mathrm{g} / \mathrm{mL})$-day for the Q2W dosing regimens and $118.5(\mu \mathrm{g} / \mathrm{mL})$-day for the QM dosing regimens. Model predictions suggested that doses of $140 \mathrm{mg}$ SC Q2W and $420 \mathrm{mg}$ SC QM achieve approximately $80 \%$ of the model-predicted maximal reduction in $\mathrm{LDL}_{\text {mean,wk10\&12. }}$. Collectively, these data suggest that both the $140 \mathrm{mg}$ SC Q2W and $420 \mathrm{mg}$ SC QM dose regimens provide exposures within the plateau region of the exposure-response relationship, supporting their use in the clinic.

In the final PK covariate model, body weight, female sex, statin co-administration, statin + ezetimibe co-administration, and PCSK9 baseline emerged as statistically significant covariates on evolocumab PK. Statin co-administration, statin + ezetimibe co-administration, and $\mathrm{HeFH}$ disease state were found to be statistically significant covariates on the exposure-response relationship. Evolocumab exposure decreased with increasing body weight. However, reduction in LDL-C at the mean of weeks 10 and 
Fig. 7 Forest plots of covariate effects with $95 \%$ CI for evolocumab $\mathrm{AUC}_{\mathrm{wk} 8-12}$ for $140 \mathrm{mg}$ SC Q2W and $420 \mathrm{mg}$ SC QM. The statin covariate represents patients only taking a statin and no other concomitant medication. The statin + Ezet covariate includes all patients on Ezet, regardless of concomitant medications. For patients in the pharmacokinetics model, $93 \%$ of those taking Ezet were also taking a statin; thus, the Ezet covariate most generally represents a combination (statin + Ezet) therapy covariate. $A U C$ area under the time-concentration curve; $C I$ confidence interval; Ezet ezetimibe; PCSK9 BL proprotein convertase subtilisin/ kexin type 9 baseline (low, $4.8 \mathrm{nM}[355 \mathrm{ng} / \mathrm{mL}]$; high, $8.1 \mathrm{nM}[599 \mathrm{ng} / \mathrm{mL}])$; $Q 2 W$ once every 2 weeks; $Q M$ once monthly; $S C$ subcutaneous a $140 \mathrm{mg}$

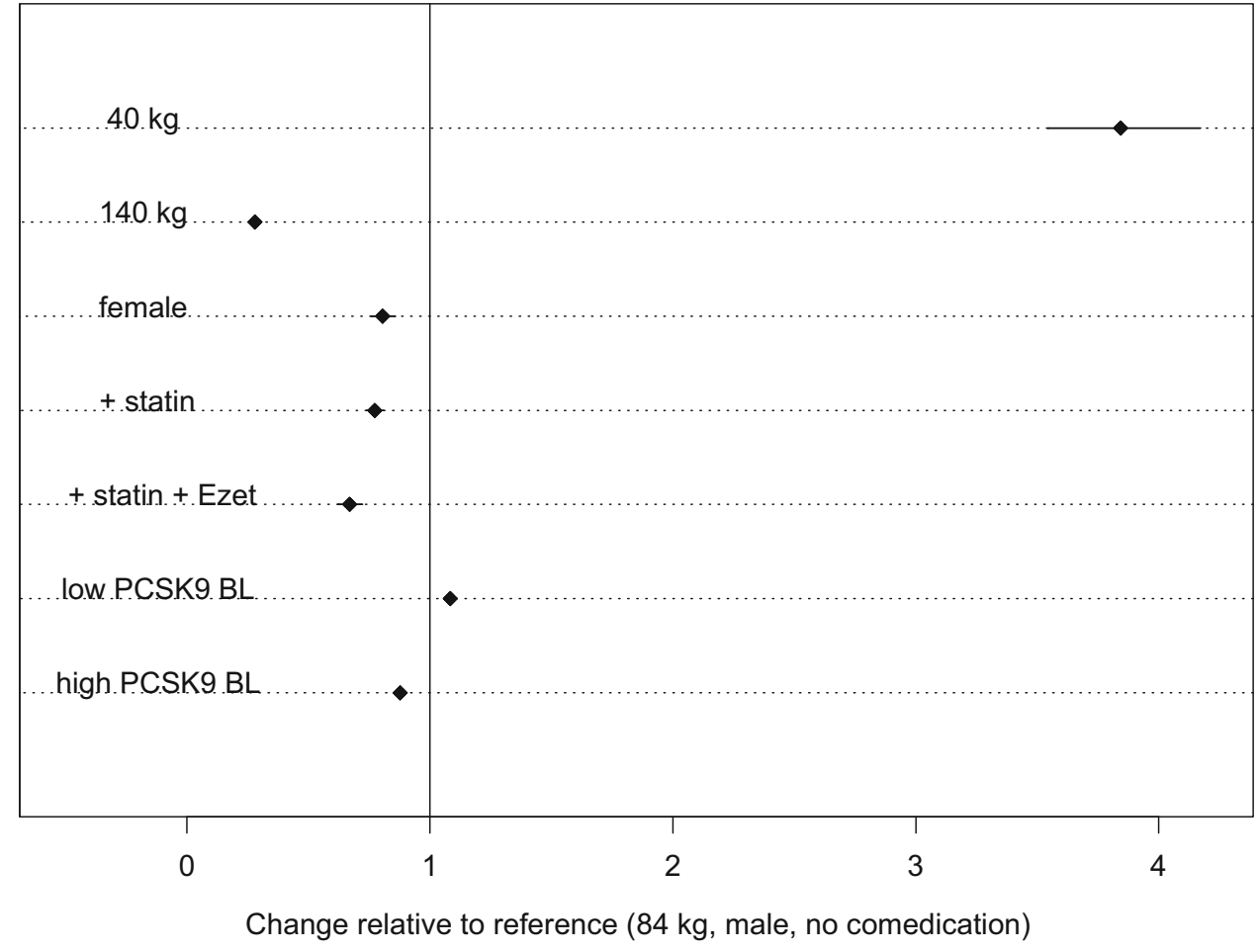

b $420 \mathrm{mg}$

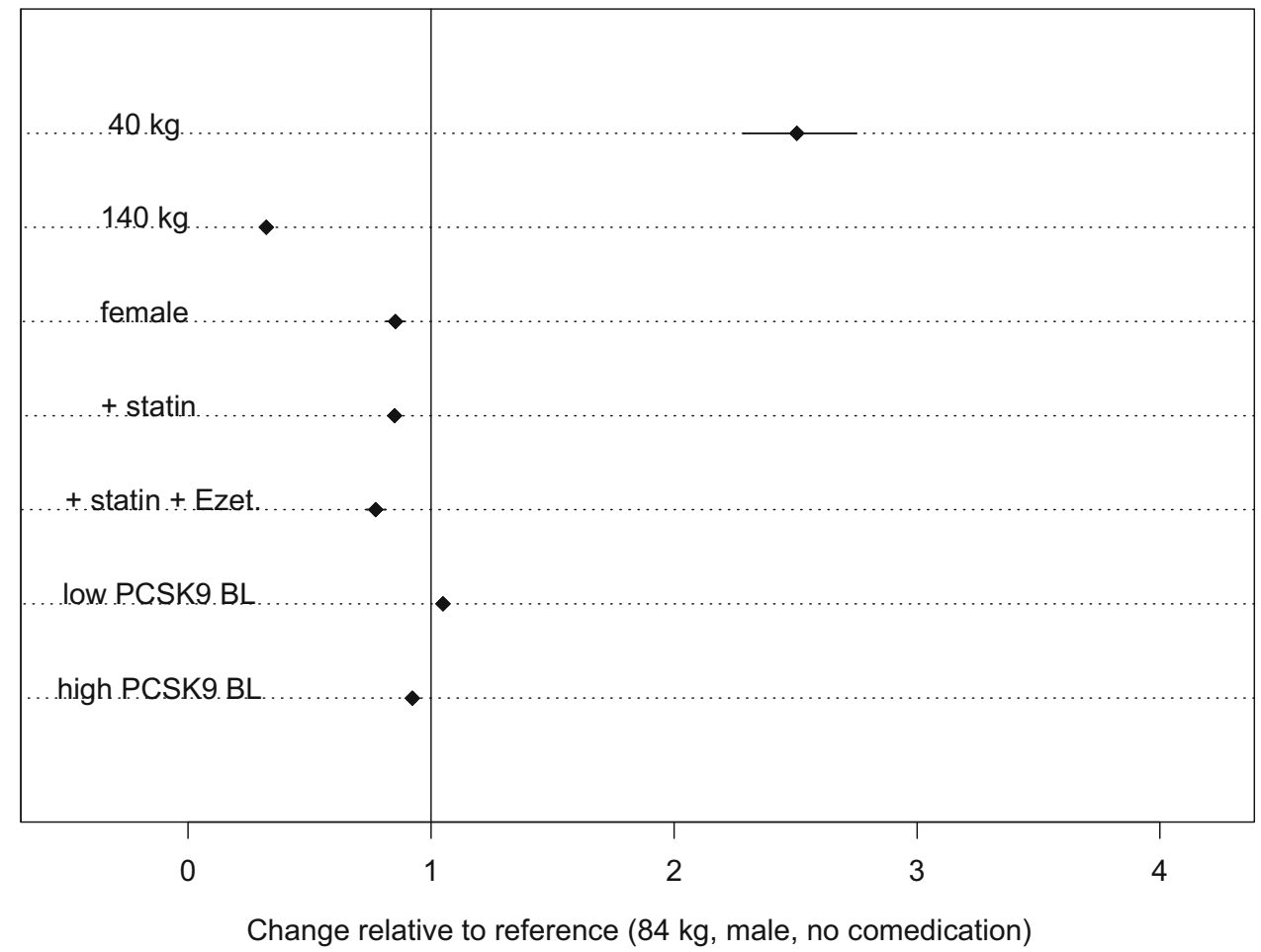

12 of evolocumab administration was predicted to be within $\pm 26 \%$ of the reference patient (an $84 \mathrm{~kg}$, male subject with hypercholesterolemia, not taking other lipid- lowering medications). Additionally, observed median LDL-C reduction at week 12 was similar across body weight quartiles $(<7 \%$ difference from lowest to highest 
Fig. 8 Forest plots of covariate effects with $95 \%$ CI for evolocumab week 10 and 12 mean calculated LDL-C lowering for $140 \mathrm{mg} \mathrm{SC} \mathrm{Q} 2 \mathrm{~W}$ and $420 \mathrm{mg}$ SC QM. CI confidence interval; Ezet ezetimibe; $\mathrm{HeFH}$ heterozygous familial hypercholesterolemia; $L D L-C$ low-density lipoproteincholesterol; PCSK9 BL proprotein convertase subtilisin/ kexin type 9 baseline (low, $4.8 \mathrm{nM}[355 \mathrm{ng} / \mathrm{mL}]$; high, $8.1 \mathrm{nM}[599 \mathrm{ng} / \mathrm{mL}])$; $Q 2 W$ once every 2 weeks; $Q M$ once monthly; $S C$ subcutaneous

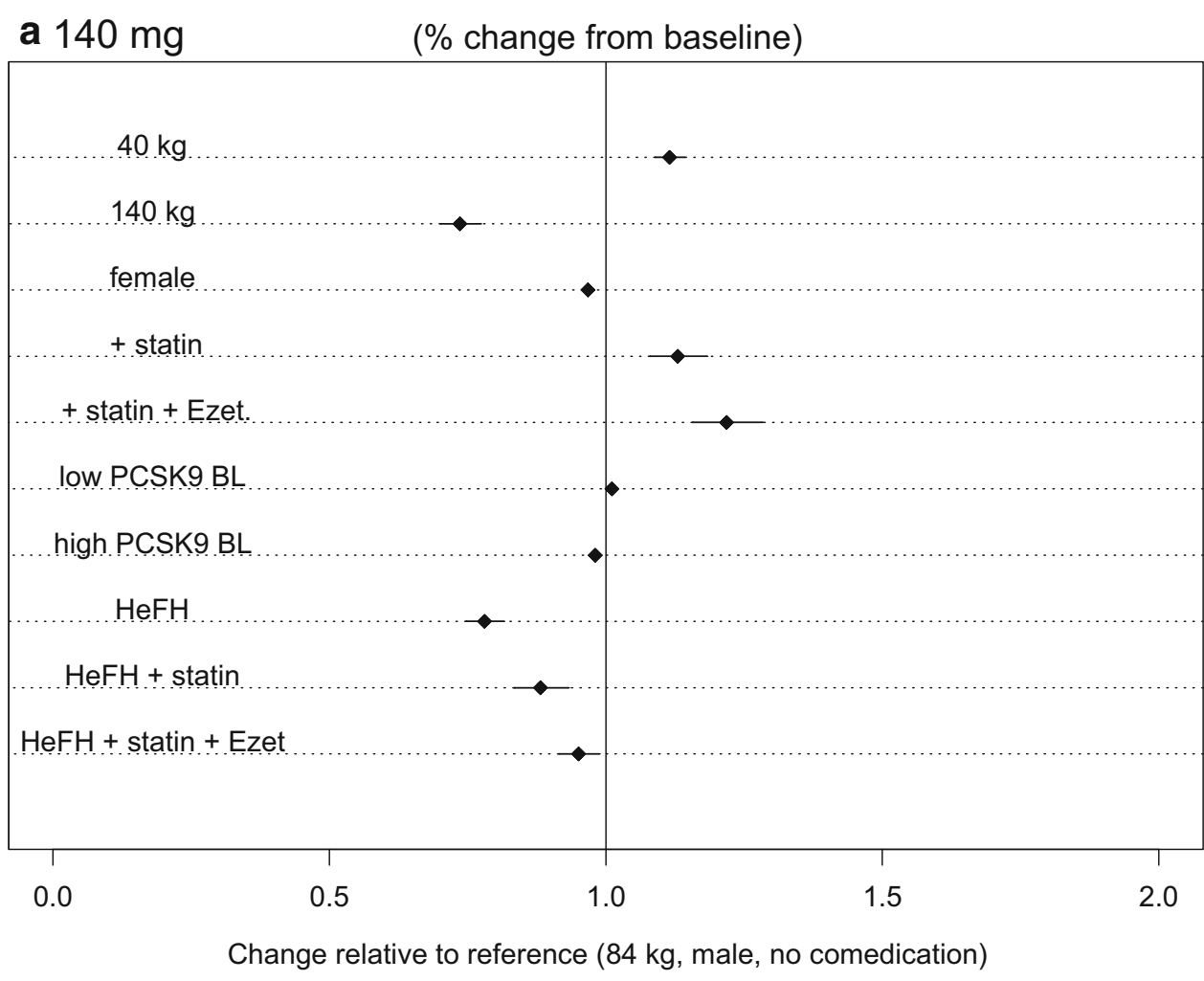

b $420 \mathrm{mg} \quad$ (\% change from baseline)

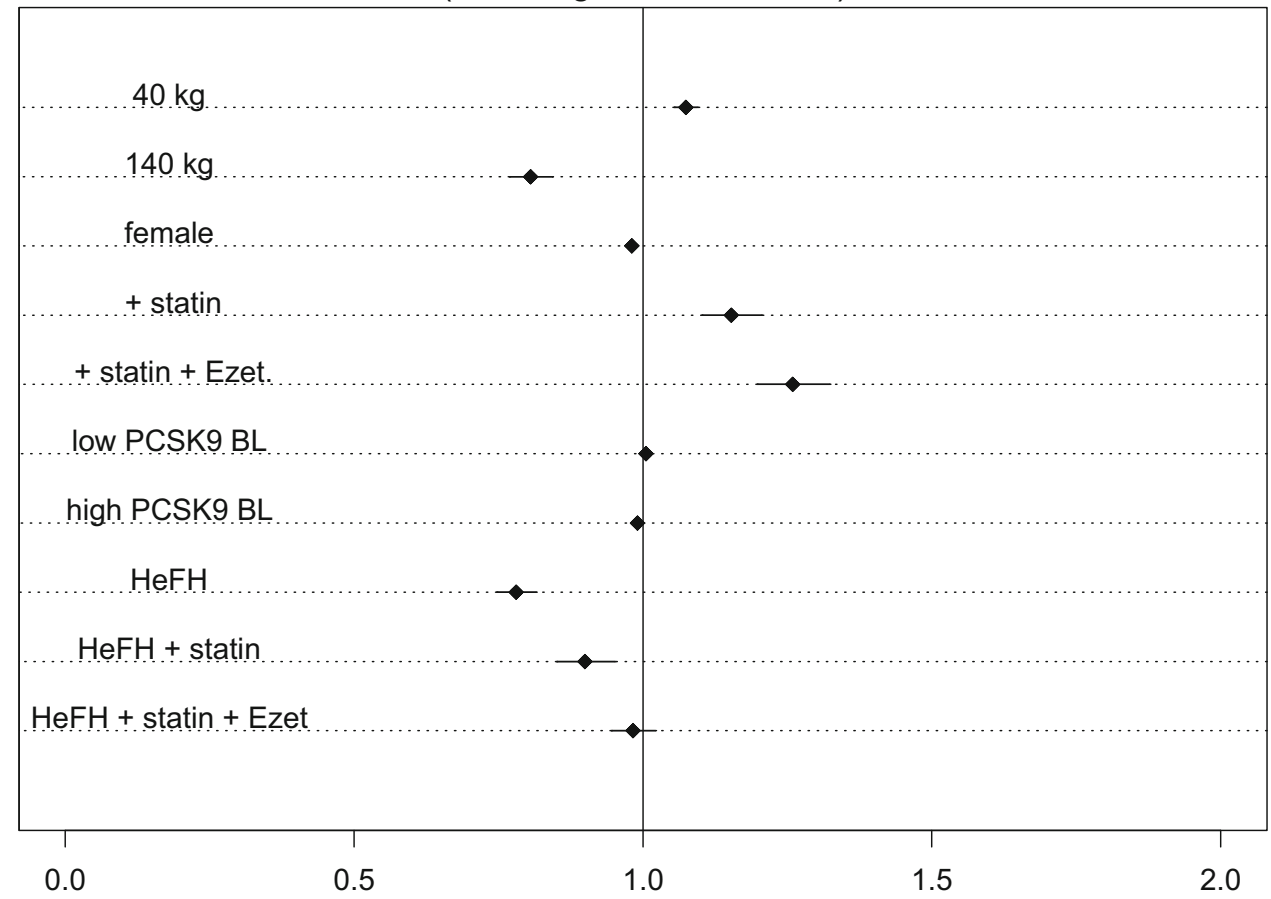

Change relative to reference ( $84 \mathrm{~kg}$, male, no comedication) quartile of body weight). Hence, dose adjustment based on body weight was not necessary. Although treatment with various statins was associated with lower unbound evolocumab exposure due to higher PCSK9 concentrations, reductions in LDL-C were comparable regardless of statin dose or intensity as reflected by changes in PCSK9 levels. 
Thus, intrinsic and extrinsic covariates, including statin coadministration, are not expected to have a clinically significant effect on the response to evolocumab treatment. Uncertainty-based simulation allows a quantitative understanding of the effect of covariates on drug response, including evaluation of "best" and "worst" case scenarios [52]. Such methodology is of particular use for therapeutics that exhibit nonlinear PK and/or exposure-response relationships, such as evolocumab, where simple extrapolations of the effects of changes in PK and PD parameters are not possible.

\section{Conclusions}

In conclusion, by incorporating multiple levels of PK and exposure-response modeling and simulation, these analyses assessed the influence of intrinsic and extrinsic covariates as sources of variability in the PK and exposureresponse relationships of unbound evolocumab. Model predictions suggested that evolocumab doses of $140 \mathrm{mg} \mathrm{SC}$ Q2W and $420 \mathrm{mg}$ SC QM achieve similar reductions in calculated LDL-C and exposures within the plateau region of the exposure-response relationship, supporting clinical use of either dose. In addition, simulations suggested that the clinical response to evolocumab is consistent across differing clinical conditions. The range of responses based on intrinsic and extrinsic factors were not predicted to be sufficiently different from the reference patient to warrant evolocumab dose adjustment.

Acknowledgements Jonathan Latham (on behalf of Amgen Inc.) and Meera Kodukulla of Amgen Inc. assisted the authors with the preparation and submission of the manuscript.

Author contributions J.P. Gibbs, A. Grover, and S. Doshi wrote the first draft of the manuscript. All authors edited the manuscript and approved the final version.

Funding This work was sponsored by Amgen Inc.

\section{Compliance with ethical standards}

Conflicts of interest M. Kuchimanchi, S.M. Wasserman, and S. Doshi are employees of and stockholders in Amgen Inc. R. Somaratne and J.P. Gibbs are identified as inventors on at least one pending patent application owned by Amgen Inc. relating to evolocumab. S.M. Wasserman appears on a number of pending patents owned by Amgen Inc. relating to evolocumab and PCSK9 inhibition. J.P. Gibbs, A. Grover, and M.G. Emery were employees of and stockholders in Amgen at the time this work was completed. J.P. Gibbs is currently employed by AbbVie, Inc. A. Grover is currently employed by BioMarin Pharmaceutical Inc. M.G. Emery is currently employed by Seattle Genetics. R. Somaratne is a stockholder of Amgen, was employed by Amgen at the time this work was completed, and is currently employed by NGM Biopharmaceuticals.
Ethical approval All studies were conducted in accordance with principles for human experimentation as defined in the Declaration of Helsinki and International Conference on Harmonization Good Clinical Practice guidelines, and approved by the relevant institutional review boards.

Informed consent Informed consent was obtained from each study participant after they were told of the potential risks and benefits as well as the investigational nature of the study.

Open Access This article is distributed under the terms of the Creative Commons Attribution 4.0 International License (http://creative commons.org/licenses/by/4.0/), which permits unrestricted use, distribution, and reproduction in any medium, provided you give appropriate credit to the original author(s) and the source, provide a link to the Creative Commons license, and indicate if changes were made.

\section{References}

1. Cholesterol Treatment Trialists (CTT) Collaboration, Baigent C, Blackwell L, Emberson J, Holland LE, Reith C, Bhala N, Peto R, Barnes EH, Keech A, Simes J, Collins R (2010) Efficacy and safety of more intensive lowering of LDL cholesterol: a metaanalysis of data from 170,000 participants in 26 randomised trials. Lancet 376(9753):1670-1681. https://doi.org/10.1016/s01406736(10)61350-5

2. Goldstein JL, Brown MS (2009) The LDL receptor. Arterioscler Thromb Vasc Biol 29(4):431-438. https://doi.org/10.1161/ATV BAHA.108.179564

3. Lagace TA (2014) PCSK9 and LDLR degradation: regulatory mechanisms in circulation and in cells. Curr Opin Lipidol 25(5):387-393. https://doi.org/10.1097/MOL.0000000000000114

4. Romagnuolo R, Scipione CA, Boffa MB, Marcovina SM, Seidah NG, Koschinsky ML (2015) Lipoprotein(a) catabolism is regulated by proprotein convertase subtilisin/kexin type 9 through the low density lipoprotein receptor. J Biol Chem 290(18): 11649-11662. https://doi.org/10.1074/jbc.M114.611988

5. Careskey HE, Davis RA, Alborn WE, Troutt JS, Cao G, Konrad RJ (2008) Atorvastatin increases human serum levels of proprotein convertase subtilisin/kexin type 9. J Lipid Res 49(2):394-398. https://doi.org/10.1194/jlr.M700437-JLR200

6. Dubuc G, Chamberland A, Wassef H, Davignon J, Seidah NG, Bernier L, Prat A (2004) Statins upregulate PCSK9, the gene encoding the proprotein convertase neural apoptosis-regulated convertase-1 implicated in familial hypercholesterolemia. Arterioscler Thromb Vasc Biol 24(8):1454-1459. https://doi.org/10. 1161/01.ATV.0000134621.14315.43

7. Mayne J, Dewpura T, Raymond A, Cousins M, Chaplin A, Lahey KA, Lahaye SA, Mbikay M, Ooi TC, Chretien M (2008) Plasma PCSK9 levels are significantly modified by statins and fibrates in humans. Lipids Health Dis 7:22. https://doi.org/10.1186/1476$511 \mathrm{X}-7-22$

8. Horton JD, Cohen JC, Hobbs HH (2009) PCSK9: a convertase that coordinates LDL catabolism. J Lipid Res 50(Suppl): S172-177. https://doi.org/10.1194/jlr.R800091-JLR200

9. Chan JC, Piper DE, Cao Q, Liu D, King C, Wang W, Tang J, Liu Q, Higbee J, Xia Z, Di Y, Shetterly S, Arimura Z, Salomonis H, Romanow WG, Thibault ST, Zhang R, Cao P, Yang XP, Yu T, Lu M, Retter MW, Kwon G, Henne K, Pan O, Tsai MM, Fuchslocher B, Yang E, Zhou L, Lee KJ, Daris M, Sheng J, Wang Y, Shen WD, Yeh WC, Emery M, Walker NP, Shan B, Schwarz M, Jackson SM (2009) A proprotein convertase subtilisin/kexin type 9 neutralizing antibody reduces serum cholesterol in mice and 
nonhuman primates. Proc Natl Acad Sci U S A 106(24):9820-9825. https://doi.org/10.1073/pnas.0903849106

10. Cicero AF, Colletti A, Borghi C (2015) Profile of evolocumab and its potential in the treatment of hyperlipidemia. Drug Des Devel Ther 9:3073-3082. https://doi.org/10.2147/dddt.s67498

11. Dias CS, Shaywitz AJ, Wasserman SM, Smith BP, Gao B, Stolman DS, Crispino CP, Smirnakis KV, Emery MG, Colbert A, Gibbs JP, Retter MW, Cooke BP, Uy ST, Matson M, Stein EA (2012) Effects of AMG 145 on low-density lipoprotein cholesterol levels: results from 2 randomized, double-blind, placebocontrolled, ascending-dose phase 1 studies in healthy volunteers and hypercholesterolemic subjects on statins. J Am Coll Cardiol 60(19):1888-1898. https://doi.org/10.1016/j.jacc.2012.08.986

12. Gibbs JP, Doshi S, Kuchimanchi M, Grover A, Emery MG, Dodds MG, Gibbs MA, Somaratne R, Wasserman SM, Blom D (2017) Impact of target-mediated elimination on the dose and regimen of evolocumab, a human monoclonal antibody against proprotein convertase subtilisin/kexin type 9 (PCSK9). J Clin Pharmacol 57(5):616-626. https://doi.org/10.1002/jcph.840

13. Blom DJ, Hala T, Bolognese M, Lillestol MJ, Toth PD, Burgess L, Ceska R, Roth E, Koren MJ, Ballantyne CM, Monsalvo ML, Tsirtsonis K, Kim JB, Scott R, Wasserman SM, Stein EA, DESCARTES Investigators (2014) A 52-week placebo-controlled trial of evolocumab in hyperlipidemia. $\mathrm{N}$ Engl $\mathrm{J}$ Med 370(19):1809-1819. https://doi.org/10.1056/NEJMoa1316222

14. Blom DJ, Djedjos CS, Monsalvo ML, Bridges I, Wasserman SM, Scott R, Roth E (2015) Effects of evolocumab on vitamin E and steroid hormone levels: results from the 52-week, phase 3, double-blind, randomized, placebo-controlled DESCARTES study. Circ Res 117(8):731-741. https://doi.org/10.1161/circresaha.115. 307071

15. Giugliano RP, Desai NR, Kohli P, Rogers WJ, Somaratne R, Huang F, Liu T, Mohanavelu S, Hoffman EB, McDonald ST, Abrahamsen TE, Wasserman SM, Scott R, Sabatine MS, LAPLACE-TIMI 57 Investigators (2012) Efficacy, safety, and tolerability of a monoclonal antibody to proprotein convertase subtilisin/kexin type 9 in combination with a statin in patients with hypercholesterolaemia (LAPLACE-TIMI 57): a randomised, placebo-controlled, dose-ranging, phase 2 study. Lancet 380(9858):2007-2017. https://doi.org/10.1016/s01406736(12)61770-x

16. Koren MJ, Lundqvist P, Bolognese M, Neutel JM, Monsalvo ML, Yang J, Kim JB, Scott R, Wasserman SM, Bays H, MENDEL-2 Investigators (2014) Anti-PCSK9 monotherapy for hypercholesterolemia: the MENDEL-2 randomized, controlled phase III clinical trial of evolocumab. $\mathrm{J}$ Am Coll Cardiol 63(23):2531-2540. https://doi.org/10.1016/j.jacc.2014.03.018

17. Koren MJ, Scott R, Kim JB, Knusel B, Liu T, Lei L, Bolognese M, Wasserman SM (2012) Efficacy, safety, and tolerability of a monoclonal antibody to proprotein convertase subtilisin/kexin type 9 as monotherapy in patients with hypercholesterolaemia (MENDEL): a randomised, double-blind, placebo-controlled, phase 2 study. Lancet 380(9858):1995-2006. https://doi.org/10. 1016/S0140-6736(12)61771-1

18. Raal F, Scott R, Somaratne R, Bridges I, Li G, Wasserman SM, Stein EA (2012) Low-density lipoprotein cholesterol-lowering effects of AMG 145, a monoclonal antibody to proprotein convertase subtilisin/kexin type 9 serine protease in patients with heterozygous familial hypercholesterolemia: the Reduction of LDL-C with PCSK9 Inhibition in Heterozygous Familial Hypercholesterolemia Disorder (RUTHERFORD) randomized trial. Circulation 126(20):2408-2417. https://doi.org/10.1161/ CIRCULATIONAHA.112.144055

19. Raal FJ, Honarpour N, Blom DJ, Hovingh GK, Xu F, Scott R, Wasserman SM, Stein EA, TESLA Investigators (2015) Inhibition of PCSK9 with evolocumab in homozygous familial hypercholesterolaemia (TESLA Part B): a randomised, doubleblind, placebo-controlled trial. Lancet 385(9965):341-350. https://doi.org/10.1016/S0140-6736(14)61374-X

20. Robinson JG, Nedergaard BS, Rogers WJ, Fialkow J, Neutel JM, Ramstad D, Somaratne R, Legg JC, Nelson P, Scott R, Wasserman SM, Weiss R, LAPLACE-2 Investigators (2014) Effect of evolocumab or ezetimibe added to moderate- or high-intensity statin therapy on LDL-C lowering in patients with hypercholesterolemia: the LAPLACE-2 randomized clinical trial. JAMA 311(18):1870-1882. https://doi.org/10.1001/jama.2014.4030

21. Stein EA, Giugliano RP, Koren MJ, Raal FJ, Roth EM, Weiss R, Sullivan D, Wasserman SM, Somaratne R, Kim JB, Yang J, Liu T, Albizem M, Scott R, Sabatine MS, PROFICIO Investigators (2014) Efficacy and safety of evolocumab (AMG 145), a fully human monoclonal antibody to PCSK9, in hyperlipidaemic patients on various background lipid therapies: pooled analysis of 1359 patients in four phase 2 trials. Eur Heart J 35(33): 2249-2259. https://doi.org/10.1093/eurheartj/ehu085

22. Stroes E, Colquhoun D, Sullivan D, Civeira F, Rosenson RS, Watts GF, Bruckert E, Cho L, Dent R, Knusel B, Xue A, Scott R, Wasserman SM, Rocco M, GAUSS-2 Investigators (2014) AntiPCSK9 antibody effectively lowers cholesterol in patients with statin intolerance: the GAUSS-2 randomized, placebo-controlled phase 3 clinical trial of evolocumab. J Am Coll Cardiol 63(23):2541-2548. https://doi.org/10.1016/j.jacc.2014.03.019

23. Sullivan D, Olsson AG, Scott R, Kim JB, Xue A, Gebski V, Wasserman SM, Stein EA (2012) Effect of a monoclonal antibody to PCSK9 on low-density lipoprotein cholesterol levels in statin-intolerant patients: the GAUSS randomized trial. JAMA 308(23):2497-2506. https://doi.org/10.1001/jama.2012.25790

24. Beal S, Sheiner LB, Boeckmann A, Bauer RJ (2009) NONMEM user's guides (1989-2009). Icon Development Solutions, Ellicott City MD

25. Gibiansky L, Gibiansky E, Kakkar T, Ma P (2008) Approximations of the target-mediated drug disposition model and identifiability of model parameters. J Pharmacokinet Pharmacodyn 35(5):573-591. https://doi.org/10.1007/s10928-008-9102-8

26. Bauer RJ (2011) NONMEM users guide: introduction to NONMEM 7.2.0. Icon Development Solutions, Ellicott City

27. Ahn JE, Karlsson MO, Dunne A, Ludden TM (2008) Likelihood based approaches to handling data below the quantification limit using NONMEM VI. J Pharmacokinet Pharmacodyn 35(4):401-421. https://doi.org/10.1007/s10928-008-9094-4

28. Beal SL (2001) Ways to fit a PK model with some data below the quantification limit. J Pharmacokinet Pharmacodyn 28(5):481-504

29. Byon W, Fletcher CV, Brundage RC (2008) Impact of censoring data below an arbitrary quantification limit on structural model misspecification. J Pharmacokinet Pharmacodyn 35(1):101-116. https://doi.org/10.1007/s10928-007-9078-9

30. Gastonguay MR (2004) A full model estimation approach for covariate effects: inference based on clinical importance and estimation precision. AAPS J 6(Suppl1):Abstract W4354

31. O'Brien L, Westwood P, Gao L, Heathman M (2017) Population pharmacokinetic meta-analysis of ramucirumab in cancer patients. Br J Clin Pharmacol 83(12):2741-2751. https://doi.org/ 10.1111/bcp. 13403

32. Ahamadi M, Freshwater T, Prohn M, Li CH, de Alwis DP, de Greef R, Elassaiss-Schaap J, Kondic A, Stone JA (2017) Modelbased characterization of the pharmacokinetics of pembrolizumab: a humanized anti-PD-1 monoclonal antibody in advanced solid tumors. CPT Pharmacometrics Syst Pharmacol 6(1):49-57. https://doi.org/10.1002/psp4.12139

33. Yao Z, Hu C, Zhu Y, Xu Z, Randazzo B, Wasfi Y, Chen Y, Sharma A, Zhou H (2018) Population pharmacokinetic modeling of guselkumab, a human IgG1 $\lambda$ monoclonal antibody targeting 
IL-23, in patients with moderate to severe plaque psoriasis. J Clin Pharmacol 58(5):613-627. https://doi.org/10.1002/jcph.1063

34. Kasichayanula S, Grover A, Emery MG, Gibbs MA, Somaratne R, Wasserman SM, Gibbs JP (2018) Clinical pharmacokinetics and pharmacodynamics of evolocumab, a PCSK9 inhibitor. Clin Pharmacokinet. https://doi.org/10.1007/s40262-017-0620-7

35. Sabatine MS, Leiter LA, Wiviott SD, Giugliano RP, Deedwania P, De Ferrari GM, Murphy SA, Kuder JF, Gouni-Berthold I, Lewis BS, Handelsman Y, Pineda AL, Honarpour N, Keech AC, Sever PS, Pedersen TR (2017) Cardiovascular safety and efficacy of the PCSK9 inhibitor evolocumab in patients with and without diabetes and the effect of evolocumab on glycaemia and risk of new-onset diabetes: a prespecified analysis of the FOURIER randomised controlled trial. Lancet Diabetes Endocrinol 5(12):941-950. https://doi.org/10.1016/S2213-8587(17)30313-3

36. Sattar N, Preiss D, Robinson JG, Djedjos CS, Elliott M, Somaratne R, Wasserman SM, Raal FJ (2016) Lipid-lowering efficacy of the PCSK9 inhibitor evolocumab (AMG 145) in patients with type 2 diabetes: a meta-analysis of individual patient data. Lancet Diabetes Endocrinol 4(5):403-410. https://doi.org/10.1016/ S2213-8587(16)00003-6

37. Sattar N, Toth PP, Blom DJ, Koren MJ, Soran H, Uhart M, Elliott M, Cyrille M, Somaratne R, Preiss D (2017) Effect of the proprotein convertase subtilisin/kexin type 9 inhibitor evolocumab on glycemia, body weight, and new-onset diabetes mellitus. Am J Cardiol 120(9):1521-1527. https://doi.org/10.1016/j.amjcard. 2017.07.047

38. Lambert G, Sjouke B, Choque B, Kastelein JJ, Hovingh GK (2012) The PCSK9 decade. J Lipid Res 53(12):2515-2524. https://doi.org/10.1194/jlr.R026658

39. Karlsson MO, Savic RM (2007) Diagnosing model diagnostics. Clin Pharmacol Ther 82(1):17-20. https://doi.org/10.1038/sj.clpt. 6100241

40. Bergsma TT, Knebel W, Fisher J, Gillespie WR, Riggs MM, Gibiansky L, Gastonguay MR (2013) Facilitating pharmacometric workflow with the metrumrg package for R. Comput Methods Programs Biomed 109(1):77-85. https://doi.org/10.1016/j.cmpb. 2012.08.009

41. Menon-Andersen D, Yu B, Madabushi R, Bhattaram V, Hao W, Uppoor RS, Mehta M, Lesko L, Temple R, Stockbridge N, Laughren T, Gobburu JV (2011) Essential pharmacokinetic information for drug dosage decisions: a concise visual presentation in the drug label. Clin Pharmacol Ther 90(3):471-474. https://doi.org/10.1038/clpt.2011.149

42. Dirks NL, Meibohm B (2010) Population pharmacokinetics of therapeutic monoclonal antibodies. Clin Pharmacokinet 49(10):633-659. https://doi.org/10.2165/11535960-00000000000000
43. Sun YN, Lu JF, Joshi A, Compton P, Kwon P, Bruno RA (2005) Population pharmacokinetics of efalizumab (humanized monoclonal anti-CD11a antibody) following long-term subcutaneous weekly dosing in psoriasis subjects. J Clin Pharmacol 45(4):468-476. https://doi.org/10.1177/0091270004272731

44. Xu Z, Vu T, Lee H, Hu C, Ling J, Yan H, Baker D, Beutler A, Pendley C, Wagner C, Davis HM, Zhou H (2009) Population pharmacokinetics of golimumab, an anti-tumor necrosis factoralpha human monoclonal antibody, in patients with psoriatic arthritis. J Clin Pharmacol 49(9):1056-1070. https://doi.org/10. 1177/0091270009339192

45. Zhu Y, Hu C, Lu M, Liao S, Marini JC, Yohrling J, Yeilding N, Davis HM, Zhou H (2009) Population pharmacokinetic modeling of ustekinumab, a human monoclonal antibody targeting IL-12/ $23 \mathrm{p} 40$, in patients with moderate to severe plaque psoriasis. J Clin Pharmacol 49(2):162-175. https://doi.org/10.1177/ 0091270008329556

46. Vugmeyster Y, Xu X, Theil FP, Khawli LA, Leach MW (2012) Pharmacokinetics and toxicology of therapeutic proteins: advances and challenges. World J Biol Chem 3(4):73-92. https:// doi.org/10.4331/wjbc.v3.i4.73

47. Wang W, Wang EQ, Balthasar JP (2008) Monoclonal antibody pharmacokinetics and pharmacodynamics. Clin Pharmacol Ther 84(5):548-558. https://doi.org/10.1038/clpt.2008.170

48. Chakraborty A, Tannenbaum S, Rordorf C, Lowe PJ, Floch D, Gram H, Roy S (2012) Pharmacokinetic and pharmacodynamic properties of canakinumab, a human anti-interleukin- $1 \beta$ monoclonal antibody. Clin Pharmacokinet 51(6):e1-e18. https://doi. org/10.2165/11599820-000000000-00000

49. Bauer RJ, Dedrick RL, White ML, Murray MJ, Garovoy MR (1999) Population pharmacokinetics and pharmacodynamics of the anti-CD11a antibody hu1124 in human subjects with psoriasis. J Pharmacokinet Biopharm 27(4):397-420

50. Hayashi N, Tsukamoto Y, Sallas WM, Lowe PJ (2007) A mechanism-based binding model for the population pharmacokinetics and pharmacodynamics of omalizumab. Br J Clin Pharmacol 63(5):548-561. https://doi.org/10.1111/j.1365-2125. 2006.02803.x

51. Kovarik JM, Nashan B, Neuhaus P, Clavien PA, Gerbeau C, Hall ML, Korn A (2001) A population pharmacokinetic screen to identify demographic-clinical covariates of basiliximab in liver transplantation. Clin Pharmacol Ther 69(4):201-209

52. Mondick JT, Gibiansky L, Gastonguay MR, Veal GJ, Barrett JS (2006) Acknowledging parameter uncertainty in the simulationbased design of an actinomycin-D pharmacokinetic study in pediatric patients with Wilms' tumor or rhabdomyosarcoma. Paper presented at the 15th Meeting of Population Approach Group Europe, Brugge/Bruges, Belgium, June 14-16 